\title{
Prudential measures in housing access: Should one include transport costs in the front-end ratio?
}

\author{
Nicolas Coulombel \\ University of Paris-Est \\ nicolas.coulombel@enpc.fr
}

\begin{abstract}
A widespread prudential measure limits the housing expense ratio-defined as the share of income spent on the rent or loan payment-to ensure household solvency. This policy is increasingly criticized, however, as it would induce households to settle far from the city center in search of lower housing prices, fostering urban sprawl. It would even prove counterproductive as high transport costs in distant areas would more than offset the lower housing costs. To avoid these unintended effects, several researchers advocate limiting the joint housing plus transport expense ratio instead. This paper aims to shed light on this issue by comparing the two prudential measures-limiting either the housing or the housing plus transport expense ratiousing the monocentric model. By constraining residential choices and reducing housing consumption, both policies improve household solvency and reduce urban sprawl. While this seems to contradict previous claims, the joint constraint proves more efficient in both regards. Provided the constraint is not too stringent, both policies have limited impact on household welfare and often even improve welfare. But this time, capping only the housing expense ratio always dominates the joint housing plus transport constraint. A numerical application to the Paris region illustrates our findings for a real case study. Results suggest that replacing the current limitation of the housing expense ratio with a joint housing plus transport constraint would significantly improve household solvency and curb urban sprawl, with a negligible welfare loss.
\end{abstract}

\section{Article history:}

Received: September 24, 2015

Received in revised form: June

24, 2016

Accepted: March 6, 2017

Available online: June 9, 2017

\section{$1 \quad$ Introduction}

The 2008 and 2011 surges in fuel prices raised concerns regarding the solvency of households, which we define here as their ability to meet all their expenses. ${ }^{1}$ The issue was especially salient in tight housing markets, where households already bear significant housing burdens. ${ }^{2}$ Although the recent drop in fuel prices has relieved households' budgets, concerns remain over the long term as fuel prices are likely to be on the rise again. Given these circumstances, the relevance of capping the housing expenditure at a fixed

Copyright 2017 Nicolas Coulombel

http://dx.doi.org/10.5198/jtlu.2017.849

ISSN: 1938-7849 | Licensed under the Creative Commons Attribution - Noncommercial License 3.0

The Journal of Transport and Land Use is the official journal of the World Society for Transport and Land Use (WSTLUR) and is published and sponsored by the University of Minnesota Center for Transportation Studies. 
fraction of the household income- a measure already questioned in the past (Hare, 1995; Polacchini \& Orfeuil, 1999)—-has become even more controversial. This prudential measure is commonly enforced in several countries to preserve the solvency of households. In France, this is achieved in two ways:

- monthly payments for home loans are capped at one third of the household gross income, $28 \%$ in the U.S., according to Duca and Rosenthal (1994);

- prospective tenants should earn at least three times the required rent to apply-leading to the same prudential ratio as in the home-buying market. ${ }^{3}$

While this policy does seem to secure the solvency of households at first sight, it may spur some households to settle far from the city center in search of lower housing prices. This is for instance the case in the Greater Paris Region. The lack of affordable housing in the central part of the metropolitan area induces new homebuyers to settle farther and farther in the suburbs, thereby fostering urban sprawl (Polacchini \& Orfeuil, 1999). Suburban households also make intensive use of the car. This exposes them to high transportation costs, which combined to the housing burden jeopardize their budget equilibrium. To prevent these unintended effects, several researchers advocate the use of a joint constraint bearing on the sum of housing and transportation expenses instead of housing only (Hare, 1995; Polacchini \& Orfeuil, 1999). Their aim is twofold: to raise public awareness of the extent of transport costs involved in suburban lifestyles, and to make near transit locations more affordable by raising home loan size (based on future savings on transport costs) for households looking to locate there.

This paper investigates whether one should include transportation costs within the prudential ratio. The current practice that limits the housing burden, referred to as the Capped Housing expense ratio policy (or $\mathrm{CH}$ policy), is compared to another including transport costs within the prudential ratio, the Capped Housing plus Transport $(\mathrm{CH}+\mathrm{T})$ expense ratio policy. The analysis is carried out using the monocentric model of urban economics. This allows us to study the effects of each policy on households (utility, budget breakdown) and on land use (city size, density, housing prices). After setting a few results in the general case, we consider a highly stylized framework: the linear city model. This specification yields closed-form solutions, which allows us to elaborate on the effects of both policies in the simplest possible manner. After extending the model to the more realistic case of elastic housing supply, we then apply it to the Greater Paris Region to provide a first appraisal of the effects of $\mathrm{CH}$ and $\mathrm{CH}+\mathrm{T}$ policies in a real case study.

The paper structure is as follows: Section 2 reviews the literature. Sections 3 and 4 investigate the effects of $\mathrm{CH}$ and $\mathrm{CH}+\mathrm{T}$ policies, respectively, using the monocentric model. Section 5 extends the model used in Sections 3 and 4 to the case of elastic housing supply. Section 6 carries out a short numerical application to the Greater Paris Region. Last, Section 7 discusses the results and concludes with policy recommendations.

\section{$2 \quad$ Literature review}

\subsection{Analysis of housing and transport burdens}

While the urban economic literature has thoroughly investigated numerous land-use regulatory policies (Bertaud \& Brueckner, 2005; Cheshire \& Sheppard, 2005; Brueckner, 2009; Turner, Haughwout, \& van der Klaauw, 2014), prudential measures enforced in housing markets have attracted less attention. Still, by studying housing and transport burdens, a first strand of the literature sheds light on the extent

\footnotetext{
${ }^{1}$ This encapsulates the standard definition of solvency as the household ability to meet its financial obligations on time, in particular mortgages.

${ }^{2}$ For the remainder of the text, we will use the terms "burden" and "expense ratio" interchangeably to refer to the share of (gross) income dedicated to a specific budget item, e.g. housing or transport. The housing expense ratio is also sometimes referred to as the front-end (or front) ratio.

${ }^{3}$ This ratio of 1 to 3 corresponds to a widespread practice in the Greater Paris Region, where some landlords may even require up to four times the rent. Income requirements may be less strict in other parts of France.
} 
to which households are effectively constrained by the maximum front-end ratio. Two elements are in fact central in motivating our paper, 1) that the $\mathrm{CH}$ policy does concern a sizable share of households, and 2) that spatial variations of transport costs do loom large relatively to the housing burden. By deriving estimates of housing and transport burdens, Polacchini and Orfeuil (1999), Berri (2007) and Coulombel and Leurent (2013) bring first pieces of answer for the Greater Paris Region. The three works draw similar conclusions:

- The housing burden is relatively stable throughout the metropolitan area and close to the maximum allowed. Polacchini and Orfeuil (1999) find that homebuyers bore in 1991 an average front ratio of $32 \%$, against $26 \%$ for private sector tenants. For the same categories, Coulombel and Leurent (2013) find respectively $28 \%$ and 39\% for year 2001. Berri (2007) provides the lowest estimates with $28 \%$ and $22 \%$ for year 1994 .

- Conversely, the transport burden rises steadily with distance to the Central Business District (CBD). This stems from a greater car mode share in the suburbs, added to longer commuting trips. In 2001, expense ratios ranged from $7 \%$ in inner Paris to $21 \%$ in the most remote parts of the Greater Paris Region (Coulombel \& Leurent, 2013).

All in all, all works point up a steady increase of the joint housing plus transport burden with distance to CBD. Quite remarkably, Haas, Makarewicz, Benedict, Sanchez, and Dawkins (2006) reach similar conclusions for the U.S., despite notorious differences with Europe relatively to common urban forms. Analyzing 28 metropolitan areas, they find the housing burden to be significantly less sensitive to location than the transport burden, which strongly increases with distance to the nearest job center. For households with yearly gross income ranging from $\$ 35,000$ to $\$ 50,000$, the mean housing burden varies between $23 \%$ and $26 \%$ depending on the location within the metropolitan area, against $16 \%$ to $26 \%$ for transportation.

The above findings lead us to two statements. The fact that the housing expense ratio is both fairly stable over the metropolitan area and close to the maximum authorized is likely linked to the limitation of the front ratio, that is, to the $\mathrm{CH}$ policy. Housing burdens strongly vary across households (Coulombel \& Leurent, 2013). Thus, an average housing burden close to the upper bound most likely implies that a sizable number of households are constrained. Furthermore, having a front ratio below the cap does not mean that you were not constrained at the time of choosing your current home. ${ }^{4}$ In other words, the number of households with housing burdens at or above the theoretical cap is probably a lower bound of the number of households concerned by the $\mathrm{CH}$ policy. ${ }^{5}$

Second, given the relative constancy of the housing burden, the rise of the transport burden with distance to CBD jeopardizes the solvency of suburban and exurban households. Households dedicating more than half their income to housing and transport are indeed no longer uncommon. Still, sound economic reasoning would object that rational and perfectly informed households choose the housingtransportation bundle that is best suited to them. Suburban households would then willingly bear high housing plus transport burdens, even it were to outweigh half their income. At least three arguments challenge this rationale:

\footnotetext{
${ }^{4}$ Income usually rises along the household lifecycle until retirement. As nominal mortgage payments are usually held constant over time, this means that the housing burden gradually declines. And when the household has reimbursed its mortgage, its housing burden decreases even further. Because rent increases are regulated, similar phenomena occur on the rental market. As a result, a household usually sees its housing burden decrease until its next residential move. The housing burden may increase in some instances however, such as in the case of an adverse event on the job market (e.g., unemployment spell), or if housing expenses increase due to particular conditions (renegotiation of the lease, flexible interest rate mortgage products, etc.).

${ }^{5}$ The housing burden may exceed the allowed limit for some households as the $\mathrm{CH}$ policy is not enforced dynamically, but in a static fashion (the capping is only checked once at the time of the residential choice).
} 
- In presence of sticky prices, ${ }^{6}$ households already settled in the city center (the "insiders") might stay to benefit from low transport costs, pushing new households (the "outsiders") towards the suburbs. The latter would enjoy lower housing prices, but that would still not compensate for the extra transport costs. Stickiness would slow the upward adjustment of housing prices in the central parts of the city, making insiders better off than outsiders.

- Households might not be perfectly informed of transport costs. In the case of car-owners, the coexistence of fixed and variable costs, the issue of maintenance, credit costs, etc., are all elements that blur the cost of car ownership. Besides, many households do not consider fixed costs in the equation. They take the fact that they need one, two or even three cars for granted, and compare the cost of transit to the variable cost of private transportation. Withal, they could save on one less car were they to locate in transit-friendly areas. Lastly, the volatility of fuel prices might be misunderstood or poorly taken into account.

- A last argument relying on moral hazard would raise the fact that households might insufficiently protect themselves against bankruptcy (from a social welfare point of view) because of laws and public policies protecting financially distressed households.

\subsection{Survey of the economic literature on $\mathrm{CH}$ and $\mathrm{CH}+\mathrm{T}$ policies}

While there is little work regarding the regulation of housing expenses on the rental market, ${ }^{7}$ the effects of borrowing constraints on housing demand have largely been documented by the economic literature (see the review by Gobillon, 2008). Most works on this topic focus on the household decision to move and on the subsequent choice of tenure. Because borrowing constraints may prevent households from choosing their optimal value of housing stock, they have the twofold impact of making tenancy more attractive and hindering residential mobility. The latter effect would even prevail according to Zorn (1989) and Gobillon and le Blanc (2008).

This literature has shed light on households' residential choices under borrowing constraints, and emphasized the significant effects of $\mathrm{CH}$ policies on homeownership markets. Most works suffer from two limitations, however. The housing supply side and subsequently equilibrium mechanisms are seldom considered, including the effect of borrowing constraints on real estate prices. Similarly, the issue of location space is rarely addressed in these works, including the few that specifically study $\mathrm{CH}+\mathrm{T}$ policies (e.g., Blackman \& Krupnick, 2001). Because housing prices strongly vary within the metropolitan area, borrowing constraints are bound to alter households' location choices. According to Hare (1995), "clunker mortgages" would even be central in accounting for urban sprawl.

\subsection{Theoretical framework: The monocentric model}

Based on the above considerations, fully understanding the effects of $\mathrm{CH}$ and $\mathrm{CH}+\mathrm{T}$ policies involves considering the role of location as well as of equilibrium mechanisms. The canonic model of urban economics, namely the monocentric model, is therefore a prime candidate. Several forms of regulation including restrictions on city size, lot size, and density (or alternatively building-height via the Floor Area Ratio) have been extensively studied in its light. ${ }^{8}$ The integrated treatment of both the demand and supply side of the housing market within a spatial framework makes it a powerful tool to analyze land-use policies. Accordingly, we will use the monocentric model to investigate the effects of $\mathrm{CH}$ and $\mathrm{CH}+\mathrm{T}$ policies, and now outline its main features. ${ }^{9}$

\footnotetext{
${ }^{6}$ The rules of numerous countries regarding rent increases strongly back the assumption of sticky prices. In France a typical lease lasts three years. Landlords cannot "freely" adjust their rents outside these time intervals, and often incur transaction costs when doing so (because it typically implies a change of tenant).

${ }^{7}$ Let us stress that regulation of housing expenses is different from rent control. The former operates at the household level, conversely to the latter which is enforced at the dwelling level through rental price ceilings and for which a vast literature exists.

${ }^{8}$ Bertaud and Brueckner (2005) and Brueckner (2009) afford a good overview of this literature.

${ }^{9}$ See Fujita (1989) for a thoroughgoing presentation of the monocentric model.
} 
In the standard version of the monocentric model, $N$ households work in the Central Business District (CBD), which is represented by a point in the center of the metropolitan area. They all earn the same income $Y$. The monocentric model aims to analyze the location choices of households within the metropolitan area, and their effects on housing supply and prices. Households maximize a utility function $U(z, s)$, where $s$ represents land consumption or lot size, and $z$ the consumption of a composite good which synthesizes all other goods in the economy. The $z$ good is taken as the numéraire, leading to the following utility maximization problem:

$$
\max _{z, s, r} U(z, s) \text { s.t. } R(r) s+z+T(r)=Y \text {, }
$$

where the variable $r$ represents location, $R(r)$ the relative land rent, and $T(r)$ transport costs. Considering that settling far from the CBD entails high transport costs, households make a trade-off between accessibility and housing prices when choosing their location. ${ }^{10}$ The crux of the model lies in the endogeneity of housing prices, reflecting the laws of supply and demand. At equilibrium, housing prices measure the spatial comparative advantage of a given location, and therefore decrease with distance to CBD.

\section{Capping the housing expense ratio}

We now amend the monocentric model to study the effects of $\mathrm{CH}$ policies. We consider the standard monocentric model of a closed city with absentee landlords and inelastic land supply. There are $N$ households who share the same income $Y$ and utility function $U(z, s)$. The utility function $U(z, s)$ and transport cost function $T(r)$ satisfy the basic assumptions:

- $U(z, s)$ is concave, strictly increases with $z$ and $s$, and is well behaved. ${ }^{11}$

- $T(r)$ increases with distance $r$ to the CBD.

As usual, we assume strictly positive land supply: $\forall r>0, L(r)>0$.

\subsection{The capped housing expense ratio $(\mathrm{CH})$ model}

\subsubsection{Model overview}

$\mathrm{CH}$ policies consist in capping the ratio of housing expenses over the household gross income. ${ }^{12}$ Accordingly, we add the following constraint to the household utility maximization problem:

$$
R(r) s \leq(1-\alpha) Y .
$$

The parameter $\alpha$, with $0 \leq \alpha \leq 1$, measures the solvency requirement level: it is the minimum income share that must be left after meeting housing expenses. The case $\alpha=0$ is equivalent to the unconstrained monocentric model, and corresponds to the unregulated situation. Conversely, if $\alpha=1$ corresponds to the opposite polar case: the solvency requirement is such that it leads to a null housing expense for all households.

Using the household budget constraint, (1) is equivalent to:

$$
z \geq \alpha Y-T(r) \text {. }
$$

\footnotetext{
${ }^{10}$ For ease of understanding, we will often favor the term "housing prices" to "land rent" in general discussions. The monocentric model assumes the rental and property markets to be at equilibrium, so that prices and rents are essentially one and the same. Moreover, we will see in Section 5 that considering housing consumption instead of land consumption does not change our main findings, supporting this conflation of the two notions.

${ }^{11}$ See definition provided in Fujita (1989) p.99.

${ }^{12}$ To keep the model simple, potential housing benefits and mortgage deductibility are not considered here. As expected, preliminary analyses show they raise the gross amount that a household can spend on housing, but do not change our main findings. See Fujita (1989) a detailed analysis of the effects of these measures.
} 
The household utility maximization problem can be rewritten:

$$
\max _{z, s, r} U(z, s) \text { s.t. }\left\{\begin{array}{l}
\mathrm{R}(r) \mathrm{s}+\mathrm{z}+\mathrm{T}(r)=Y, \\
\mathrm{z} \geq \alpha \mathrm{Y}-\mathrm{T}(\mathrm{r})
\end{array}\right.
$$

We introduce several notations. The farthest feasible location is noted $r_{\text {max }}$, with $T\left(\mathrm{r}_{\max }\right)=Y$. By noting $z(r, u)$ the solution of the bid-max problem for the unconstrained case (see below), we define two specific subsets of $\left[0, r_{\max }\right]$ :

- $E_{A}(u, \alpha)=\{r / z(r, u)<\alpha Y-T(r)\}$ is the strictly binding zone for a given utility level $\mathrm{u}$ and a given constraint level $\alpha$. It is the set of locations where households effectively limit their housing consumption because of the $\mathrm{CH}$ policy.

- $E_{I}(u, \alpha)=\overline{E_{A}(u, \alpha)}$ is the complementary of $E_{A}(u, \alpha)$. It is the nonbinding zone, where households are not affected by the $\mathrm{CH}$ policy. The open subset of $E_{I}(u, \alpha)$ is noted $\breve{E}_{I}(u, \alpha)$.

Last, a tilde is added to the variable names when referring to the $\mathrm{CH}$ model, in contrast to the original unconstrained model for which no tilde is used.

\subsubsection{The bid-max problem}

Following Fujita (1989), the bid-rent function is defined as the maximum land rent per surface unit that a household can offer at location $r$ given a target utility $u$ :

$$
\tilde{\Psi}(r, u)=\max _{z, s}\left\{\frac{Y-T(r)-z}{s} \mid \begin{array}{l}
U(z, s)=u \\
z \geq \alpha Y-T(\dot{r})
\end{array}\right\}
$$

The argmax of the bid-max problem are noted $(z(r, u), s(r, u))$ in the unconstrained case and $(\widetilde{z}(r, u), \tilde{s}$ $(r, u))$ in the $\mathrm{CH}$ case. We have three main results in the former case (Fujita, 1989): 1) lot size $s(r, u)$ increases with distance $r$ to $\mathrm{CBD}$ and utility $u, 2)$ bid rent $\Psi(r, u)$ decreases with $r$ and $u$, and finally 3$)$ the consumption of the composite good $z(r, u)$ decreases with $\mathrm{r}^{13}$ Let $S(z, u)$ and $Z(s, u)$ denote the inverse functions of $U(z, s)$ with regard to $s$ and $z$.

\section{Lemma 1}

In the CH model, the bid-max variables are given by:

$$
\left\{\begin{array}{l}
\tilde{z}(r, u)=\max [z(r, u), \quad \alpha Y-T(r)] \\
\tilde{s}(r, u)=\min [s(r, u), S(\alpha Y-T(r), u)] \\
\widetilde{\Psi}(r, u)=\min [\Psi(r, u),(1-\alpha) Y \widetilde{s}(r, u)]
\end{array}\right.
$$

\section{Proof}

See Appendix.

Lemma 1 implies that $\widetilde{z}(r, u) \geq z(r, u), \tilde{s}(r, u) \leq s(r, u)$ and $\tilde{\Psi}(r, u) \leq \Psi(r, u)$. Capping the housing expense ratio reduces the demanded lot size and the ability to pay per unit of land. ${ }^{14}$ Moreover, (3) entails that:

- $\tilde{s}(r, u, \alpha)$ increases with $r$ and $u$, and decreases with $\alpha$;

- $\widetilde{\Psi}(r, u, \alpha)$ decreases with $r, u$, and $\alpha$;

- $\tilde{z}(r, u, \alpha)$ decreases with $r$ and increases with $\alpha$.

Conservation of variational properties with respect to $r$ and $u$ will later prove central when demonstrating the existence and uniqueness of the land use equilibrium in the $\mathrm{CH}$ model. Regarding the role of $\alpha$, raising the constraint lowers the maximum level of housing expenses, which pushes households to

\footnotetext{
${ }^{13}$ There is no specific result regarding the influence of $\mathrm{u}$ on $\mathrm{z}(\mathrm{r}, \mathrm{u})$.

${ }^{14} \mathrm{This}$ is for a given utility level. Because the $\mathrm{CH}$ constraint entails changes in the equilibrium utility level, we will see that $\mathrm{CH}$ policies may actually lead to larger lots than in the unconstrained city.
} 
purchase smaller lots, to decrease their bid rent, and to increase their consumption of the $z$ good.

\subsubsection{Existence and uniqueness of the $\mathrm{CH}$ equilibrium}

Following Fujita (1989), establishing the existence and uniqueness of the equilibrium in the $\mathrm{CH}$ model is equivalent to proving that there exists a single couple $\left(\widetilde{u}, \widetilde{r}_{f}\right)$ that satisfies:

$$
\left\{\begin{array}{l}
\tilde{\Psi}\left(\tilde{r}_{\mathrm{f}}, \tilde{u}\right)=R_{A} \\
\int_{0}^{\tilde{f} f} n(r) d r=N
\end{array}\right.
$$

The upper equation is the boundary condition that determines the edge $\tilde{r}_{f}$ of the city: at $\tilde{r}_{f}$ the bid rent function equates the opportunity cost of land $R_{A}$. The lower equation represents the population constraint: integrating density $n(r)$ within the city yields total population $N$. Density $n(r)$ is obtained by dividing the available land supply by the land consumption per household: $n(r)=L(r) / \widetilde{s}(r, \widetilde{u})$.

\section{Proposition 1}

\section{The CH model admits a unique equilibrium.}

\section{Proof}

See Appendix.

\subsection{Comparative statics in the general case}

We study the influence of the constraint parameter $\alpha$ on the main equilibrium features.

\subsubsection{City size}

As the solvency requirement becomes more stringent, the size of the city decreases:

\section{Proposition 2}

The size $\tilde{r}_{f}(\alpha)$ of the $C H$ city decreases with $\alpha$.

\section{Proof}

See Appendix.

$\mathrm{CH}$ cities are always smaller than unregulated cities (given by $\alpha=0$ ), whatever the value of $\alpha$. This is conform to intuition, inasmuch as the $\mathrm{CH}$ constraint reduces bid-max lot sizes. ${ }^{15}$

\subsubsection{Equilibrium utility}

Limiting the front-end ratio generates two opposite forces:

- because they are constrained in their choices, for a given land rent level households achieve a lower utility than in the unconstrained situation;

- but capping housing expenses has a downward effect on bid prices, and subsequently on equilibrium land rents, which raises household utility (through an income effect).

Depending on the relative magnitude of the two forces, the $\mathrm{CH}$ city will have a greater or lower equilibrium utility than the unregulated city. Proposition 3 sheds light on this issue:

${ }^{15}$ This point was not trivial. The equilibrium utility of the $\mathrm{CH}$ city may for some values of $\alpha$ be greater than for the unregulated city, which usually involves a larger city size in the monocentric model. This means that the downward effect of the $\mathrm{CH}$ constraint on bid-max lot sizes always prevails on the utility effect. 


\section{Proposition 3}

Consider $0 \leq \alpha_{1}<\alpha_{2} \leq 1$. If the household located at the edge of the $\alpha_{1}$ city spends less than $\left(1-\alpha_{2}\right) Y$ on housing, the equilibrium utility $\tilde{u}\left(\alpha_{2}\right)$ of the $\alpha_{2}$ city is greater than $\tilde{u}\left(\alpha_{1}\right)$.

\section{Proof}

See Appendix.

As long as the solvency requirement is not too stringent (i.e., that the household located at the city edge remains unconstrained), the equilibrium utility increases with $\alpha$. By setting $\alpha_{1}=0$, Proposition 3 also provides a sufficient (but not necessary) criterion for the $\mathrm{CH}$ city to display a greater equilibrium utility than the unregulated city. We will see in subsection 3.3 that if the constraint is too strong, the utility of the $\mathrm{CH}$ city falls and tends toward 0 , however.

\subsubsection{Household budget breakdown}

The influence of $\alpha$ on housing expenses is not trivial, because tightening the constraint may yield a lower utility level, which may raise the housing budget of unconstrained households. When utility increases, raising $\alpha$ always decreases the total land rent accruing to landlords. This point holds true if the entire city is constrained (see Appendix).

\subsection{Application to a linear city}

Considering the limitations of the general case, we consider in the next two subsections the special case of a linear city $L(r)=1$ with linear transport costs $T(r)=a r$ and of households with Cobb-Douglas preferences $U(z, s)=z^{1 / 2} s^{1 / 2}$. This will allow us to derive closed-form solutions and thereby elaborate on the effects of $\mathrm{CH}$ policies in the simplest possible manner.

\subsubsection{Binding zone}

Under Cobb-Douglas preferences, households allow fixed fractions of their disposable income to each budget item, in our case one half for housing and the other for the $z$ composite good. Consequently, the housing budget in the unconstrained case is $R(r) s(r, u)=1 / 2(Y-a r)$, and the $\mathrm{CH}$ constraint (1) is strictly binding if and only if $r<r_{\text {bind }}(\alpha)=(2 \alpha-1) Y / a$, where $r_{\text {bind }}(\alpha)$ sets the end of the binding zone $E_{\mathrm{A}}(u, \alpha)$. This leads to two alternatives (Figure 1):

- if $\alpha \leq 1 / 2$, the solvency constraint is loose and never binding; the $\mathrm{CH}$ model is equivalent to the unconstrained model.

- if $\alpha>1 / 2$, households located before $r_{\text {bind }}(\alpha)$ are subject to the $\mathrm{CH}$ constraint.

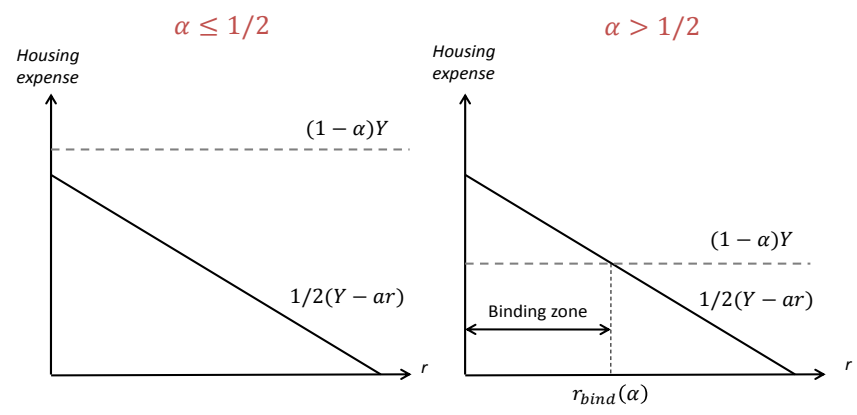

Figure 1: Illustration of the binding zone for $\alpha \leq 1 / 2$ and $\alpha>1 / 2$

Note: the unconstrained housing budget is depicted in plain line, while the $\mathrm{CH}$ constraint appears in dashes. 


\subsection{2 \\ Bid-max variables}

Solving the bid-max problem yields:

$$
\mathrm{r} \leq \mathrm{r}_{\text {bind }}(\alpha)\left\{\begin{array}{l}
\tilde{z}(r, u)=\alpha Y \text {-ar } \\
\tilde{s}(r, u)=u^{2} / \tilde{z}(r, u) \\
\left.\tilde{\Psi}(r, u)=(1-\alpha) Y(\alpha Y-a r) / u^{2}\right)
\end{array} \quad \mathrm{r} \geq \mathrm{r}_{\text {bind }}(\alpha)\left\{\begin{array}{l}
\tilde{z}(r, u)=(Y \text {-ar }) / 2 \\
\tilde{s}(r, u)=u^{2} / \tilde{z}(r, u) \\
\left.\tilde{\Psi}(r, u)=(Y-a r)^{2} / 4 u^{2}\right)
\end{array}\right.\right.
$$

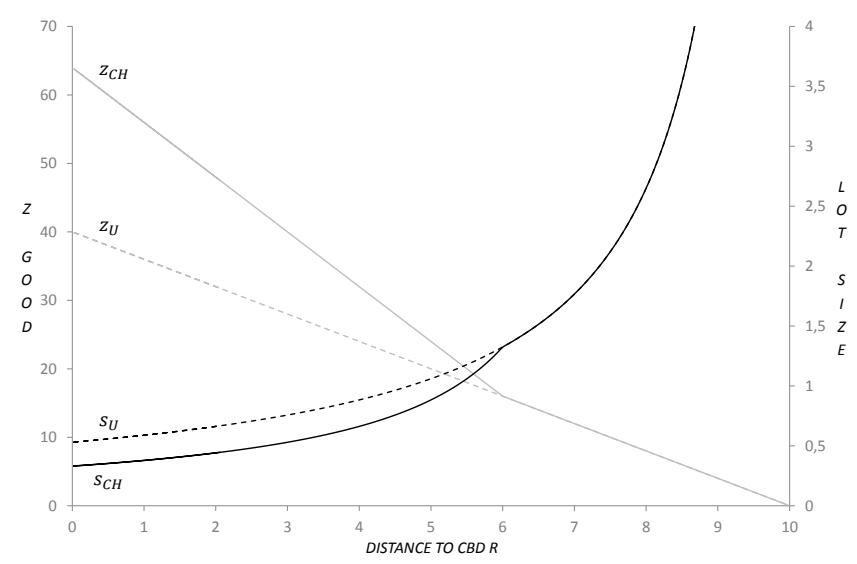

Figure 2A: Lot size and z good consumption in the unconstrained $(\mathrm{U})$ and $\mathrm{CH}$ models

Figure 2 illustrates the bid-max variables for the following parameter values: $N=10, Y=80, a=8$, and $R_{A}=20$. The $\mathrm{CH}$ constraint and utility levels are set at $\alpha=0.80$ and $u=4.61$, respectively. ${ }^{16}$ For these settings, we have $r_{\max }=10$ and $r_{\text {bind }}=6$.

As shown in subsection 3.1.2, $\mathrm{CH}$ policies reduce lot sizes and bid rents within the binding zone, while increasing consumption of the composite good. Beyond the binding zone, we find the same solutions for the $\mathrm{CH}$ and unconstrained models. ${ }^{17}$

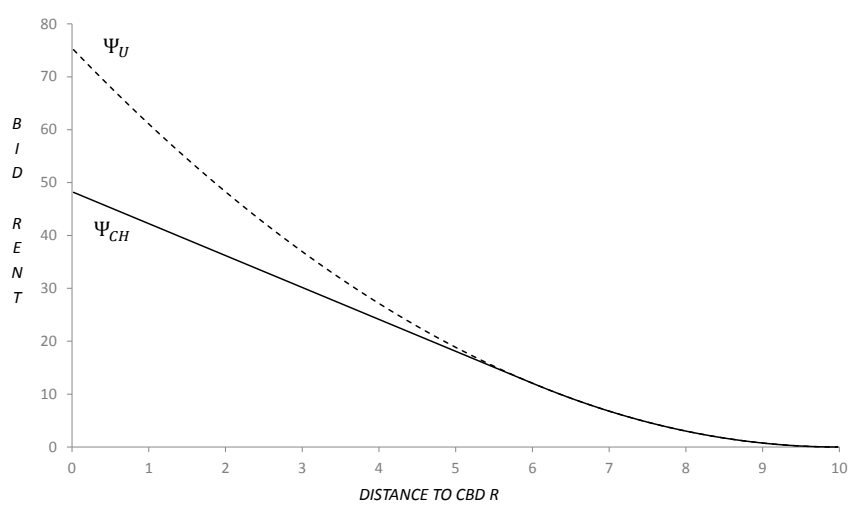

Figure 2B: Bid rent functions in the unconstrained $(\mathrm{U})$ and $\mathrm{CH}$ models

\footnotetext{
${ }^{16}$ The value $u=4.61$ corresponds to the equilibrium utility level of the $\mathrm{CH}$ model for the chosen parameter values. The equilibrium utility for the unconstrained model is $u=4$ (see Figure 3). For our illustrations we use $u=4.61$ in both cases, however. This aims to bring forward the distortive effect of the $\mathrm{CH}$ constraint on bid-max variables (for a given utility level), which is less conspicuous when adding the variation in utility ( $c f$. subsection 3.2.20).

${ }^{17}$ Again, this is for similar utility levels. At equilibrium, the utility of the $\mathrm{CH}$ model may be greater or lower than for the unconstrained model, with subsequent changes in the bid-max variables.
} 
In the linear $\mathrm{CH}$ city, the equilibrium land use is given by (see proof in Appendix):

\begin{tabular}{|c|ccc|}
\cline { 2 - 4 } \multicolumn{1}{c|}{} & $0 \leq \alpha \leq 1 / 2$ & $1 / 2 \leq \alpha \leq \alpha_{c r}$ & $\alpha_{c r} \leq \alpha \leq 1$ \\
\hline$\tilde{u}(\alpha)^{2}$ & $\frac{1}{4} \frac{Y^{2}}{a N+R_{A}}$ & $\left(\frac{1}{4}+\left(\alpha-\frac{1}{2}\right)^{2}\right) \frac{Y^{2}}{a N+R_{A}}$ & $\frac{(1-\alpha)^{2} Y^{2}}{R_{A}}\left(\sqrt{\left(\frac{a N}{R_{A}}\right)^{2}+\left(\frac{\alpha}{1-\alpha}\right)^{2}}-\frac{a N}{R_{A}}\right)$ \\
$\widetilde{r_{f}}(\alpha)$ & $\frac{Y}{a}\left(1-\sqrt{\frac{R_{A}}{a N+R_{A}}}\right)$ & $\frac{Y}{a}\left(1-\sqrt{1+(2 \alpha-1)^{2}} \sqrt{\frac{R_{A}}{a N+R_{A}}}\right)$ & $\frac{Y}{a}\left(1-(1-\alpha)\left(1+\sqrt{\left(\frac{a N}{R_{A}}\right)^{2}+\left(\frac{\alpha}{1-\alpha}\right)^{2}}-\frac{a N}{R_{A}}\right)\right)$ \\
\hline
\end{tabular}

where $\alpha_{c r}=\sqrt{R_{A}+2 a N} /\left(\sqrt{R_{A}}+\sqrt{R_{A}+2 a N}\right)$ is the threshold value of $\alpha$ above which the entire CH city is constrained. Calculations are based on the distinction of three regimes:

- $\alpha \leq 1 / 2$ yields the unconstrained model;

- If $1 / 2 \leq \alpha \leq \alpha_{c r}$, the city edge is beyond $r_{b i n d}(\alpha)$, meaning that the most remote households are not impacted by the constraint;

- If $\alpha \geq \alpha_{c r}$ all households are constrained.

\subsection{Comparative statics in the linear city model}

Using the results from subsection 3.3.3, we study the influence of the constraint level $\alpha$ on households (utility, budget composition) and land use (city size, density).

\subsubsection{Equilibrium utility}

In the linear city model, raising $\alpha$ increases household utility at first, but if the $\mathrm{CH}$ constraint is too stringent utility decreases (except in the special case $R_{A}=0$ ).

\section{Proposition 4}

If $R_{A}>0$, the equilibrium utility $\tilde{u}(\alpha)$ in the linear $C H$ city is first constant, strictly increases, and finally decreases, with $\tilde{u}(\alpha) \underset{\alpha \rightarrow 1}{\longrightarrow} 0$.

If $R_{A}=0$, the equilibrium utility $u(\alpha)$ is first constant then strictly increases.

\section{Proof}

See Appendix.

If outside competition for land (as measured by $R_{A}$ ) is mild, the distorting effect of the $\mathrm{CH}$ constraint on households' consumption choices is more than compensated for by lower land rents within the binding zone. This raises utility for all households. If the $\mathrm{CH}$ constraint causes the household competitiveness to be too weak relatively to the agricultural sector however, the effect of a reduction in city size is accentuated and causes the decline in utility.

Figure 3 illustrates the variations of $\widetilde{\mathrm{u}}(\alpha)$ in the case of our reference model. ${ }^{18}$

\subsubsection{City size}

Unlike utility, increasing $\alpha$ always reduces city size (Figure 3), as established by Proposition 2 . The way it occurs varies depending on the value of $\alpha$, however. If utility rises, higher densities near the CBD

${ }^{18}$ For reminder the reference model corresponds to $N=10, Y=80, a=8$ and $R A=20$; for these settings $\alpha_{c r}=0.75$. 
overweigh lower densities in the suburban area, hence a smaller city (Figure 4). When utility decreases-which is when the $\mathrm{CH}$ constraint is too strong relatively to the need to compete for land with the agricultural sector- density uniformly rises throughout the city, which causes city size to decrease ever more rapidly. All in all, $\mathrm{CH}$ policies lead to steeper density gradients throughout the city (Figure 4).

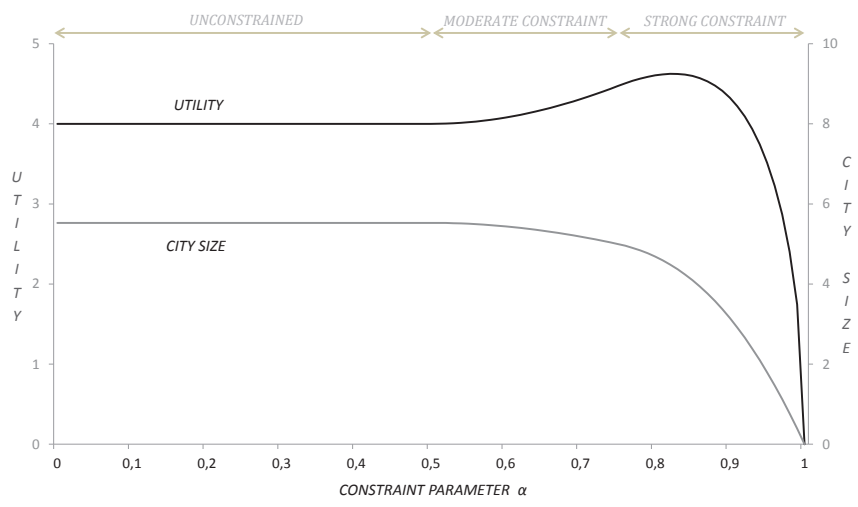

Figure 3: Influence of $\alpha$ on equilibrium utility and city size

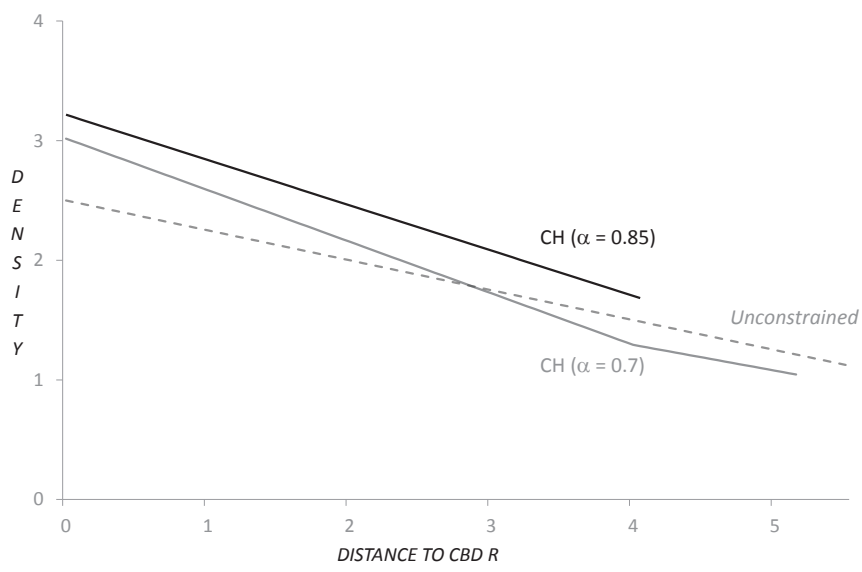

Figure 4: Influence of $\alpha$ on equilibrium densities

\subsubsection{Household budget breakdown}

Because $\mathrm{CH}$ policies are intended to protect the solvency of households, one key issue lies in the average composition of the household budget at the equilibrium land use:

\section{Proposition 5}

In the linear city model, the average housing and transport burdens both decrease with $\alpha$, entailing a higher consumption of the $z$ good.

\section{Proof}

See Appendix. 
Figure 5 illustrates Proposition 5 for the reference model. For moderate values of $\alpha$ (between 0.5 and 0.6), increasing $\alpha$ barely reduces housing and transport burdens, as only a limited fraction of households are affected by the constraint. As $\alpha$ increases further, housing expenses decrease more sharply while transport costs remain moderately affected. On this interval, decreasing $\alpha$ has a more significant downward effect on prices than on lot sizes. Beyond a certain value (around $\alpha=0.85$ ), the constraint weighs more on households' choices of lot size, resulting in a decrease in city size as well as in transport costs.

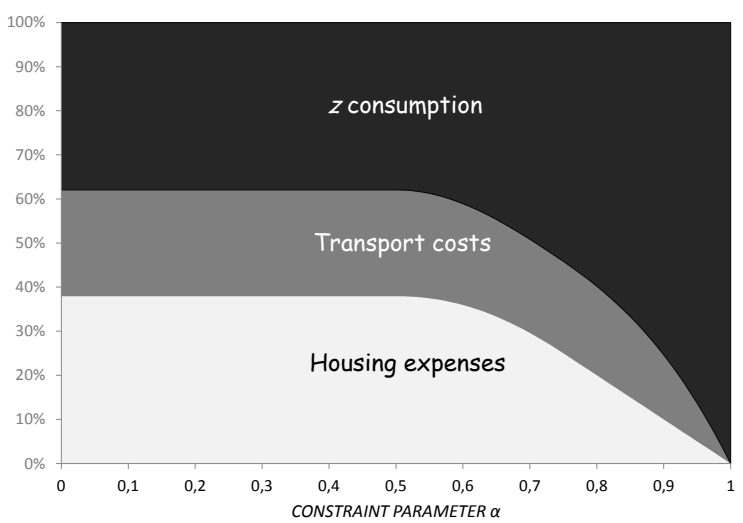

Figure 5: Influence of $\alpha$ on the average composition of the household budget

\section{$4 \quad$ Capping the joint housing plus transport expense ratio}

We now consider the alternative prudential measure that caps the joint housing plus transport expense ratio. As previously, we study the effect of the policy on the equilibrium land use, with a specific attention to the influence of the constraint parameter $\mu$.

Considering the strong similarities between the $\mathrm{CH}$ and $\mathrm{CH}+\mathrm{T}$ models, we present the results in the general case while omitting proofs, to focus on the application to the linear city. More detailed results regarding the $\mathrm{CH}+\mathrm{T}$ model may be found in Appendix. This time a hat is added to variable names when referring to the $\mathrm{CH}+\mathrm{T}$ model.

\subsection{The capped housing + transport $(\mathrm{CH}+\mathrm{T})$ expense ratio model}

\subsubsection{Model overview}

Again, we amend the monocentric model by introducing the new constraint:

$$
R(r) s+T(r) \leq(1-\mu) Y
$$

The sum of housing and transport expenses is capped at a fraction $(1-\mu)$ of the household gross income. Equivalently, $\mu$ represents the minimum share of income that must remain for the sole consumption of the $z$ composite good. As a matter of fact, (5) is equivalent to:

$$
z \geq \mu Y
$$

As previously, the case $\mu=0$ corresponds to the unconstrained model. 
$\mathrm{CH}+\mathrm{T}$ policies generate effects similar to $\mathrm{CH}$ policies: they constrain household choices regarding lot size (they de facto set a minimum net density) ${ }^{19}$, and lower land prices by limiting the household bidding power. But unlike $\mathrm{CH}$ policies, they firstly affect remote households, starting from the city edge. The tighter the constraint, the more households are subject to it, until the whole city is effectively constrained.

\subsubsection{Equilibrium features in the general case}

Equilibrium for the $\mathrm{CH}+\mathrm{T}$ model exists and is unique. ${ }^{20}$ As mentioned above, the $\mathrm{CH}+\mathrm{T}$ constraint induces the same forces as in the $\mathrm{CH}$ case: it forces households to make sub-optimal choices, which decreases the equilibrium utility, but also leads to lowers land rents, which raises utility. Unlike for $\mathrm{CH}$ policies, there is no obvious case where one can predict the outcome regarding the utility level. The same holds true for housing expenses and total differential land rent. Therefore, the only specific property in the general case is that city size decreases with $\mu$, which stems from the minimum net density enforcement. ${ }^{21}$

\subsection{Application to a linear city}

We consider the same linear city model as in Section 3, with $U(z, s)=z^{1 / 2} s^{1 / 2}, T(r)=a r$ and $L(r)=1$.

\subsubsection{Binding zone}

Following the same reasoning as in subsection 3.3.1, it is straightforward to show that the $\mathrm{CH}+\mathrm{T}$ constraint (5) is strictly binding if and only if $r>r_{\text {bind }}(\mu)=(1-2 \mu) Y l a$, where $r_{\text {bind }}(\mu)$ sets the beginning of the binding zone. Hence the two following possibilities:

- If $\mu \leq 1 / 2$, only households located beyond $r_{b i n d}(\mu)$ are constrained.

- If $\mu>1 / 2$, the entire city is constrained.

We define $\mu_{c r}$ as the first value of $\mu$ for which the $\mathrm{CH}+\mathrm{T}$ constraint is effective (i.e., if $\mu<\mu_{c r}$ no household is constrained and we are faced with the unconstrained model).

\subsection{2}

\section{Bid-max variables}

$$
r \leq r_{\text {bind }}(\mu) \quad\left\{\begin{array}{l}
\hat{z}(r, u)=(Y-a r) / 2 \\
\hat{s}(r, u)=u^{2} / \tilde{z}(r, u) \\
\hat{\Psi}(r, u)=(Y-a r)^{2} / 4 u^{2}
\end{array} \quad r \leq r_{\text {bind }}(\mu) \quad\left\{\begin{array}{l}
\tilde{z}(r, u)=\mu Y \\
\tilde{s}(r, u)=u^{2} / \tilde{z}(r, u) \\
\tilde{\Psi}(r, u)=\mu Y((1-\mu) Y-a r) / u^{2}
\end{array}\right.\right.
$$

Figure 6 illustrates the bid-max variables for the reference model. ${ }^{22}$ If $r \leq r_{\text {bind }}(\mu)$, the $\mathrm{CH}+\mathrm{T}$ constraint is not binding and consumption choices are identical to the unconstrained model. If $r>r_{\text {bind }}(\mu)$, the constraint leads to constant choices of lot size and of the $z$ good.

\footnotetext{
${ }^{19}$ At equilibrium, all households share the same utility $\hat{u}(\mu)$. The $\mathrm{CH}+\mathrm{T}$ constraint $z \geq \mu Y$ therefore implies that $s \leq S(\mu Y, \hat{u}(\mu))$. Lot size cannot exceed a certain value, which is equivalent to setting a minimum net density. See also Appendix for more details on this point.

${ }^{20}$ Proof of Proposition 1 may be easily adapted to demonstrate this point.

${ }^{21}$ Again, proof of Proposition 2 is easily adapted.

${ }^{22}$ The reference model is characterized by the following parameter values: $N=10, Y=80, a=8, R_{A}=20$. In addition, we set $\mu=$ 0.30 and $u=4$, hence $r_{\max }=7$ and $r_{\text {bind }}=4$. The value $u=4$ corresponds to the equilibrium utility of the $\mathrm{CH}+\mathrm{T}$ model for this specific set of parameters (and is coincidentally that of the unconstrained model
} 


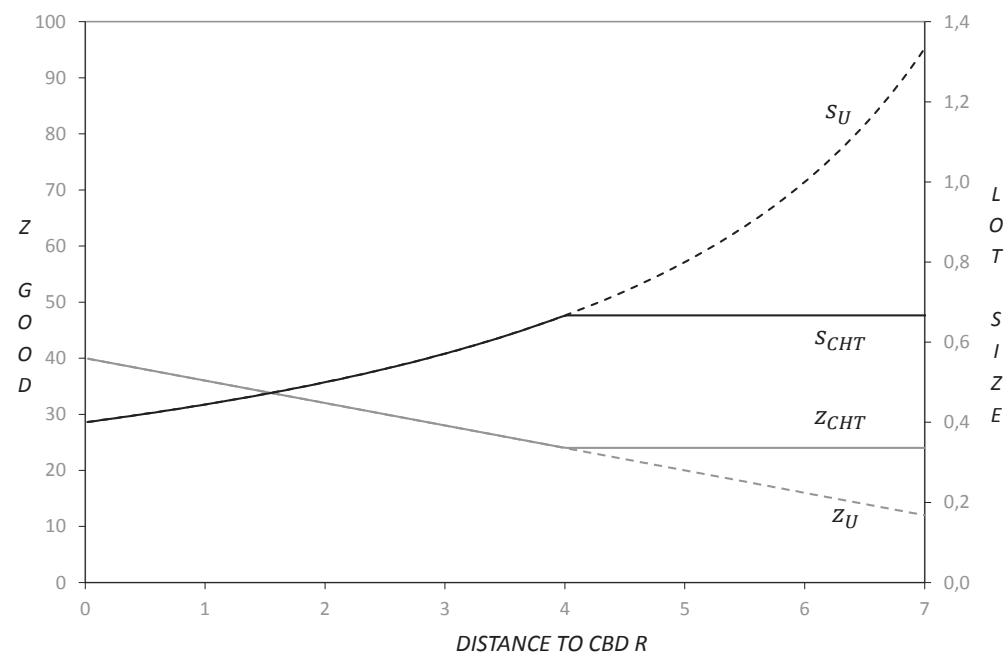

Figure 6A: Lot size and z good consumption in the unconstrained $(\mathrm{U})$ and $\mathrm{CH}+\mathrm{T}$ models

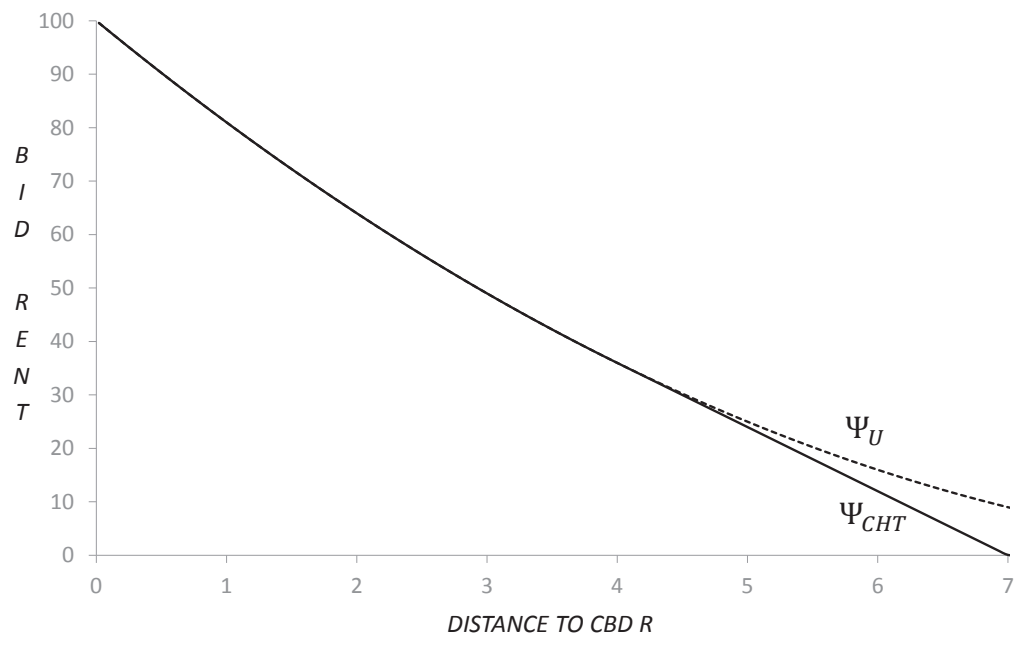

Figure 6B: Bid rent functions in the unconstrained $(\mathrm{U})$ and $\mathrm{CH}+\mathrm{T}$ models

\subsubsection{Analytical derivation of the equilibrium land use}

In the linear $\mathrm{CH}+\mathrm{T}$ city, the equilibrium land use is given by (see proof in Appendix):

\begin{tabular}{|l|ccc|}
\cline { 2 - 4 } \multicolumn{1}{c|}{} & $\mu \leq \mu_{c r}$ & $\mu_{c r} \leq \mu \leq 1 / 2$ & $\mu \geq 1 / 2$ \\
\hline$\hat{u}(\mu)^{2}$ & $\frac{1}{4} \frac{Y^{2}}{a N+R_{A}}$ & $\frac{1}{4} \frac{Y^{2}}{a N+R_{A}}$ & $\mu(1-\mu) \frac{Y^{2}}{a N+R_{A}}$ \\
$\widehat{r}_{f}(\mu)$ & $\frac{Y}{a}\left(1-\sqrt{\frac{R_{A}}{a N+R_{A}}}\right)$ & $\frac{Y}{a}\left(1-\frac{1}{2}\left(\frac{\mu}{\mu_{c r}}+\frac{\mu_{c r}}{\mu}\right) \sqrt{\frac{R_{A}}{a N+R_{A}}}\right)$ & $(1-\mu) \frac{a N}{a N+R_{A}} \frac{Y}{a}$ \\
\hline
\end{tabular}

where $\mu_{c r}=\frac{1}{2} \sqrt{\frac{R_{A}}{R_{A}+a N}}$. 
Again, calculations are based on the distinction of three cases:

- $\mu \leq \mu_{c r}$ yields the unconstrained model.

- $\mu_{c r} \leq \mu \leq 1 / 2$ is the intermediate case in which only households living in the central part of the city (i.e., $\left.\left[0, r_{\text {bind }}(\mu)\right]\right)$ are unconstrained.

- If $\mu \geq 1 / 2, r_{\text {bind }}(\mu) \leq 0$ and the entire city is constrained.

\subsection{Comparative statics in the linear city model}

\subsubsection{Equilibrium utility}

Straightforwardly, $\hat{\mathrm{u}}(\mu)$ is constant if $\mu \leq 1 / 2$, then strictly decreases. For $\mu_{c r} \leq \mu \leq 1 / 2$, the decrease in land rents exactly offsets the effect on lot sizes, hence a constant utility level. If $\mu \geq 1 / 2$, the constraint becomes too strong: the lot size effect prevails and utility falls.

Figure 7 plots $\hat{u}(\mu)$ in the case of the reference model (with $\left.\mu_{c r}=0.224\right)$ :

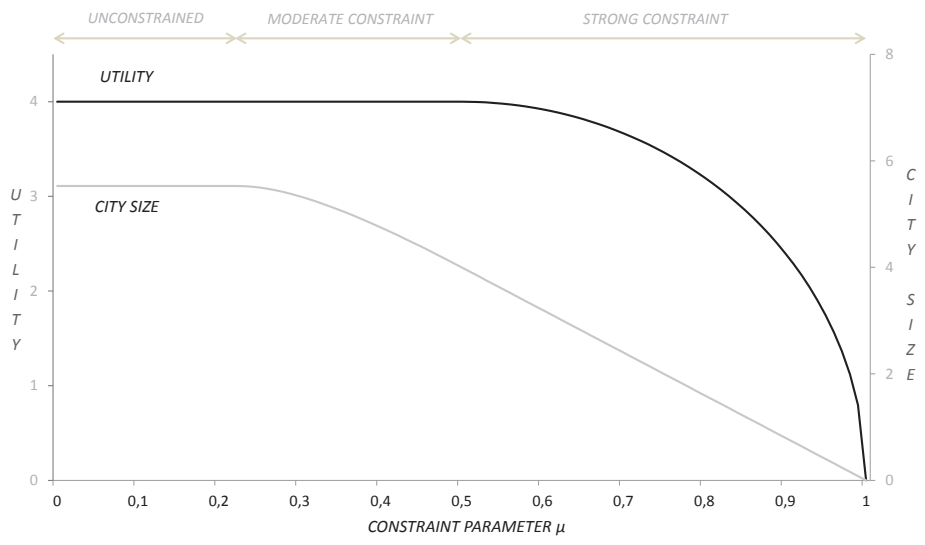

Figure 7: Influence of $\mu$ on equilibrium utility and city size

\subsubsection{City size}

As mentioned in subsection 4.1.2, city size decreases with $\mu$, whatever the parameter values. Starting from $\mu_{c r}$ (before, the constraint is innocuous), the effects of the $\mathrm{CH}+\mathrm{T}$ policy are barely sizable at first, but quickly city size dwindles

This shows the efficiency of this policy to curb urban sprawl (relatively to $\mathrm{CH}$ policies). If $\mu \geq 1 / 2$, city size decreases linearly.

Unlike $\mathrm{CH}$ policies, $\mathrm{CH}+\mathrm{T}$ policies lead to more homogeneous densities across the city. Indeed, as mentioned previously $\mathrm{CH}$ policies de facto enforce a minimum net density level, which affects either only part of or the whole city depending on whether $\mu \lesseqgtr 1 / 2$ (Figure 8 ). This accounts for the linearity of city size if $\mu \geq 1 / 2$. 


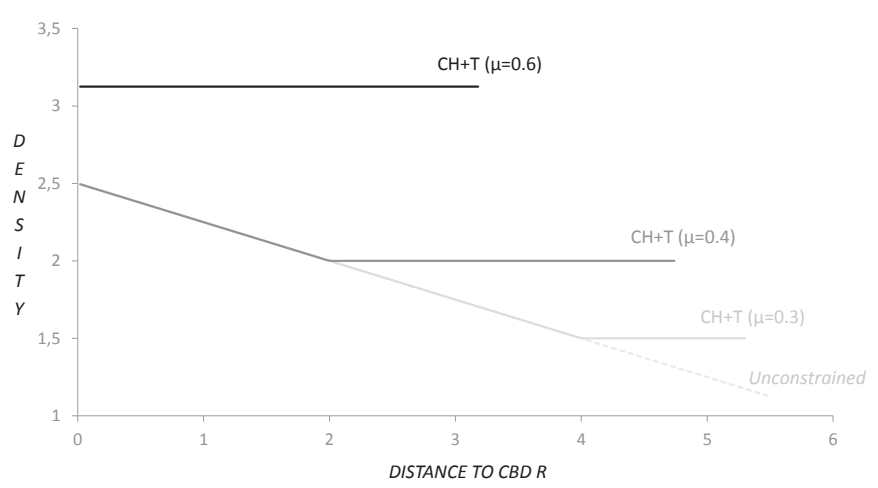

Figure 8: Influence of $\mu$ on equilibrium densities

\subsubsection{Household budget breakdown}

Similarly to $\mathrm{CH}$ policies, $\mathrm{CH}+\mathrm{T}$ policies reduce both households' housing and transport outlays (which is indeed the very goal of these policies):

\section{Proposition 6}

In the linear city model, the average housing and transport burdens both decrease with $\mu$, hence an increasing mean consumption of the composite good.

\section{Proof}

See Appendix.

When the $\mathrm{CH}+\mathrm{T}$ policy becomes active (i.e., $\mu \geq \mu$ ), raising $\mu$ results in lower transport costs as well as housing expenses. The two items decrease in similar proportions this time, due to the joint consideration of housing and transport instead of housing only within the budget constraint. If $\mu>1 / 2$, the constraint gets too strong, and the decrease steepens.

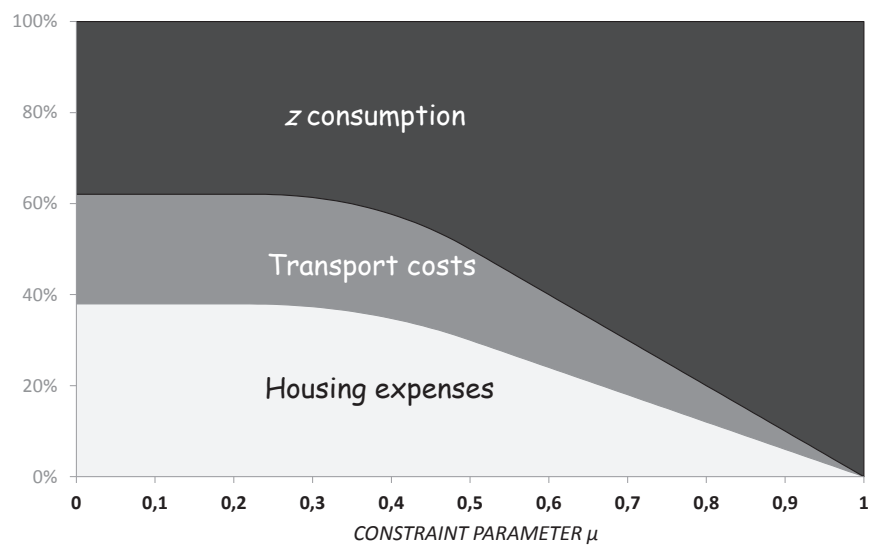

Figure 9: Influence of $\mu$ on the average composition of the household budget 


\section{$5 \quad$ Extension: Elastic housing supply}

In the previous sections, we have considered the simplest version of the monocentric model, in which households directly consume land (rather than housing) and land supply is inelastic.

We have seen in Sections 3 and 4 that $\mathrm{CH}$ and $\mathrm{CH}+\mathrm{T}$ measures lead to lower housing prices. One would expect real estate developers to react accordingly by reducing housing supply, a retroactive effect which is not captured by the "land version" of the monocentric model. This could change our findings inasmuch as lower housing supply is detrimental to households; in particular, it might reduce or even offset the utility gain observed in the $\mathrm{CH}$ case. To address this issue, we extend the $\mathrm{CH}$ and $\mathrm{CH}+\mathrm{T}$ models developed in Sections 3 and 4 by considering elastic housing supply (which also involves that households consume housing services instead of land as previously). Then, we illustrate to what extent this changes our findings in the case of our reference linear city model.

Following Muth (1969), we represent the housing industry as perfectly competitive and as being characterized by a Cobb-Douglas production function: $H(K, L)=H_{0} K^{\epsilon} L^{1-\epsilon}$. Firms use $L$ units of land and $K$ units of capital to produce $H(K, L)$ units of housing services. The parameter $\epsilon$ measures the elasticity of substitution between capital and land, while $H_{0}$ is a model constant. Considering that the land rent is given by $R_{L}(\mathrm{r})$ and the cost of capital is $\delta$, the profit function of real estate developers reads: $\Pi(K, L)=R_{\mathrm{H}}$ (r) $H(K, L)-R_{L}(r) L-\delta K$, where $R_{H}(r)$ is the unit price (or unit rent to be specific) of housing services at location $r$. Firms being profit-maximizers, the optimal level of capital $K^{*}$ is given by:

$$
\frac{K^{*}}{L}=\left(\frac{\epsilon H_{0} R_{H}(r)}{\delta}\right)^{\frac{1}{1-\epsilon}}
$$

The optimal level of housing services at location $\mathrm{r}$ is thus $H\left(K^{*}, L\right)=H_{0} L\left(\epsilon H_{0} R_{H}(r) / \delta\right)^{\frac{\epsilon}{1-\epsilon}}$.

Built density $H\left(K^{*}, L\right) / L$ increases with housing price $R_{H}(r)$ with an elasticity $\epsilon /(1-\epsilon)>0$. This conforms to the stylized fact that the higher the level of housing prices, the higher the built density at a given location.

To emphasize the fact that households now consume housing services instead of land, their utility is written $U(z, q)$, where $q$ measures the consumption level of housing services. Similarly, the population density $n(r)$ used in the equilibrium condition relative to the population constraint (lower equation in (4)) is now given by $n(r)=H\left(K^{*}(r), L(r)\right) / q(r, u)$ instead of $n(r)=L(r) / s(r, u)$ as in Sections 3 and 4.

Representing the housing industry makes the algebra substantially more complex. Formal derivation of the linear case in particular is no longer feasible. Given these limitations, we illustrate the effect of elastic housing supply by studying the influence of the parameter $\epsilon$, the elasticity of substitution between land and capital (which also measures the price elasticity of housing supply), on the equilibrium solution in the case of our reference linear city model.

As expected, elastic housing supply mitigates the welfare effects (positive or negative) of $\mathrm{CH}$ and $\mathrm{CH}+\mathrm{T}$ prudential measures. Let us consider the $\mathrm{CH}$ case. If housing supply is inelastic $(\epsilon=0)$-as assumed in Sections 3 and 4 -the maximum utility gain is around 15\% (Figure 10). But as housing supply gets more elastic the maximum gain falls to around $3 \%$ for $\epsilon=0.25$ and is null for $\epsilon=0.5$. The decrease in housing prices caused by the $\mathrm{CH}$ policy entails a downward adjustment of housing supply. The lower supply mitigates the welfare improving income effect of the $\mathrm{CH}$ policy, and may even cancel it if the price elasticity of housing supply is too great. The opposite occurs for $\mathrm{CH}+\mathrm{T}$ policies: though barely discernable on Figure 10, the housing industry does (very) slightly mitigate the decrease in utility caused by the $\mathrm{CH}+\mathrm{T}$ policy. 


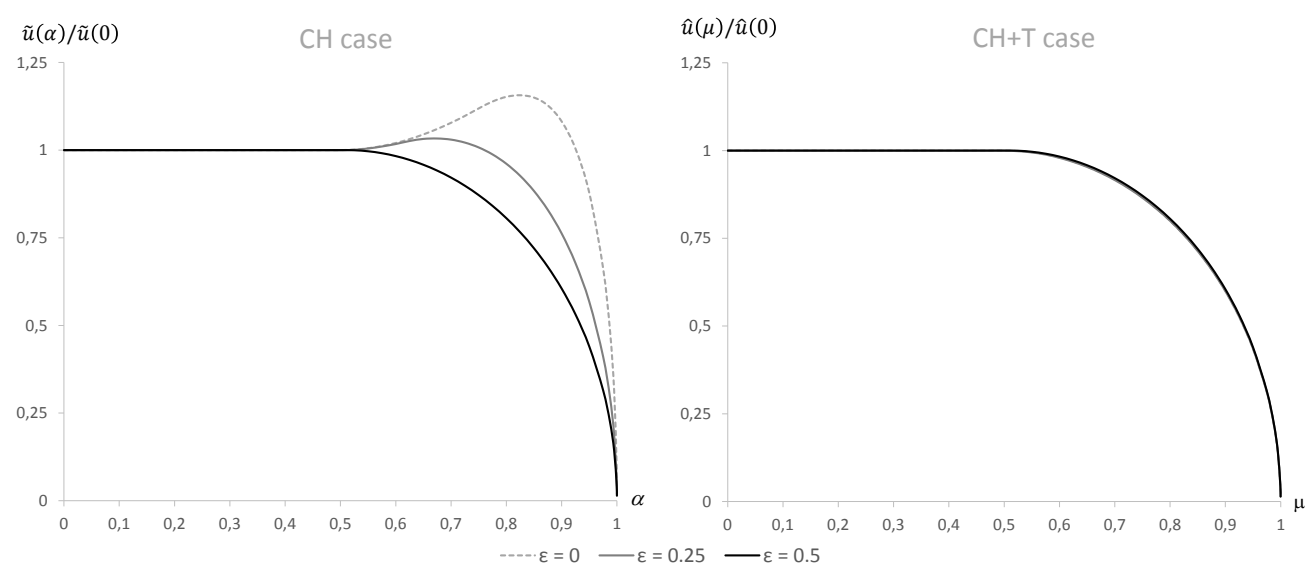

Figure 10: Influence of $\mu$ on equilibrium utility

Note: Utility levels are provided in relative terms. This aims to make the comparison between the different values of $\epsilon$ easier, as the starting point of each curve (the equilibrium utility in the unconstrained case) would vary with the value of $\epsilon$, otherwise. The above curves therefore measure the relative gain/loss in utility compared to the unconstrained situation as a function of the constraint parameter $\alpha$ ( $\mathrm{CH}$ case) or $\mu(\mathrm{CH}+\mathrm{T}$ case).

The influence on city size is less trivial. In the $\mathrm{CH}$ case, an increase in $\epsilon$ exacerbates the decrease in city size, while the opposite occurs in the $\mathrm{CH}+\mathrm{T}$ case (Figure 11). Elastic housing supply leads to higher built densities near the $\mathrm{CBD}$, and to lower built densities in the suburbs. Compared to the inelastic case, there is consequently more population living close to the $\mathrm{CBD}$. In the $\mathrm{CH}$ case, reduction in city size primarily stems from the lower housing consumption of households close to the CBD (see 3.4.2). The effect is accentuated with elastic housing supply, as more households live near the CBD and are forced to decrease their housing consumption. In the $\mathrm{CH}+\mathrm{T}$ case, reduction in city size is mainly the fact of suburban households (see 4.2.2). Because the latter are less numerous when housing supply is elastic, the impact on city size is mitigated this time.

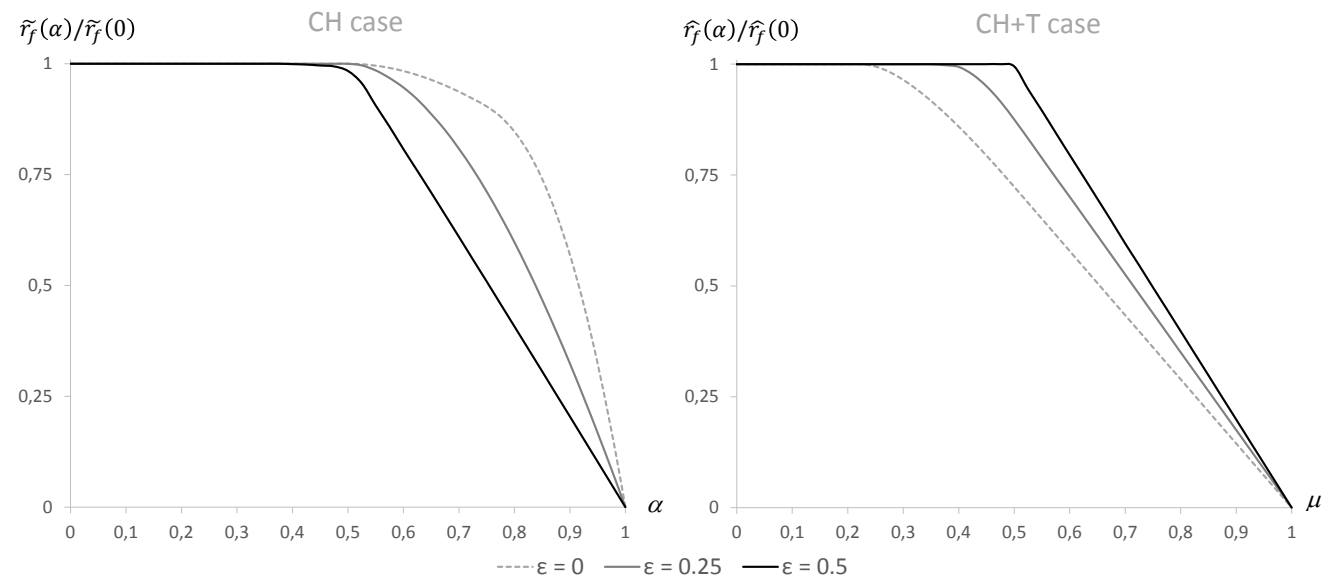

Figure 11: Influence of $\epsilon$ on equilibrium city size

Note: Again, city sizes are provided in relative terms (compared to the unconstrained situation). 


\section{Application to the Greater Paris Region}

We now briefly investigate the case of the Greater Paris Region. Rather than precise figures, which would imply using a much more sophisticated model, this short numerical application intends to provide a first appraisal of the effects of $\mathrm{CH}$ and $\mathrm{CH}+\mathrm{T}$ policies in a real case study. The study area of the Greater Paris Region is especially relevant in this regard. As discussed in subsection 2.1, housing is very expensive, in particular in the central parts of the metropolitan area and firstly Paris. Similarly, transport costs in suburban areas are high, due to an extensive use of the car. $\mathrm{CH}$ and $\mathrm{CH}+\mathrm{T}$ prudential measures are thus likely to yield significant effects. Moreover, employment remains strongly localized around the CBD of Paris and La Défense, meaning that the monocentric assumption is valid to some extent (Viguié, Hallegatte, \& Rozenberg, 2014).

We utilize for the numerical application the extended model developed in Section 5. Parameter values were extracted from a number of sources and correspond to year 2008. Household population and gross income are provided by Census and fiscal databases from Insee (French national institute for statistics), respectively. Transport costs were extracted from Coulombel and Leurent (2013). ${ }^{23}$ All remaining parameters (household utility function, housing production function, cost of capital) were borrowed from Viguié et al. (2014). ${ }^{24}$ Parameter values are as follows: $N=4863000, Y=3000 €, U(z, s)=z^{0.6} s^{0.4}$, $T(r)=0.014 r, L(r)=2 \pi \theta(r) r$ with $\theta(r)=0.5 e^{-r / 7000}, R_{A}=12 € / \mathrm{m}^{2}, H(K, L)=2.014 K^{0.36} s^{0.64}$ and last $\delta=5 \%$.

We first investigate the effects of $\mathrm{CH}$ and $\mathrm{CH}+\mathrm{T}$ policies on household solvency. Solvency is measured as the fraction of the household (gross) income that remains after meeting housing and transport expenses, which are treated as compulsory. ${ }^{26}$ For both policies, increasing the constraint parameter improves household solvency (Figure 12). $\mathrm{CH}+\mathrm{T}$ policies reduce inequalities between households much more strongly than $\mathrm{CH}$ policies do, however. By jointly considering housing and transport instead of housing only, $\mathrm{CH}+\mathrm{T}$ policies ultimately prove more efficient than $\mathrm{CH}$ policies in improving household solvency as a whole.

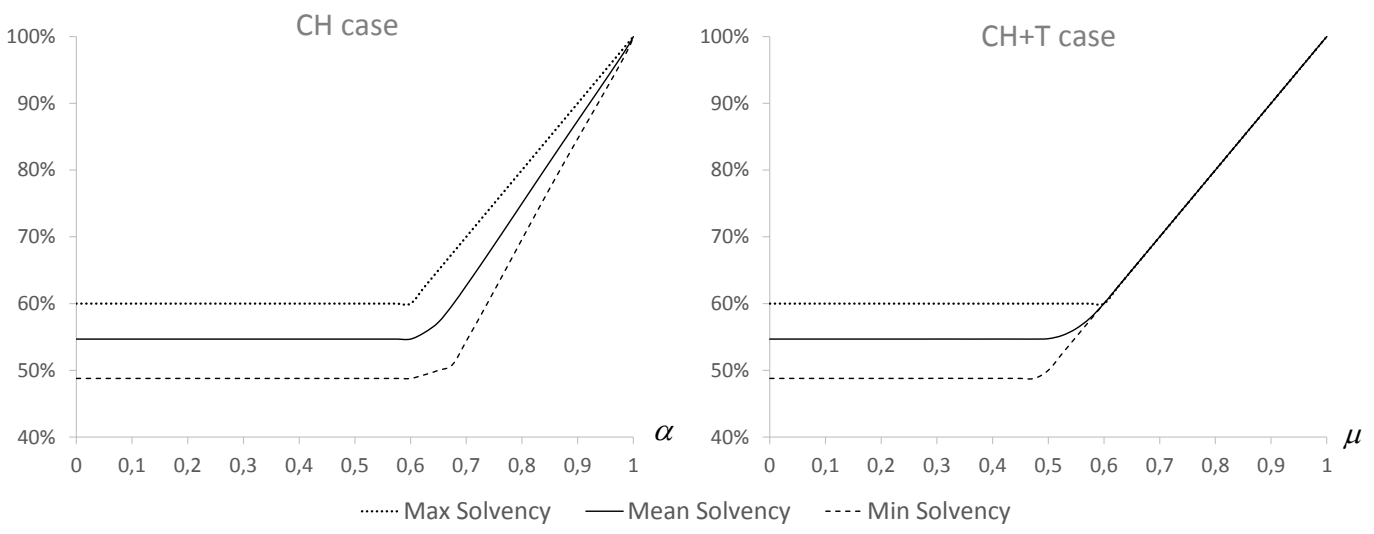

Figure 12: Influence of $\mathrm{CH}$ and $\mathrm{CH}+\mathrm{T}$ constraint levels on household solvency (Greater Paris Region)

${ }^{23}$ The authors compute the mean transport burden for a subdivision in 8 zones of the Greater Paris Region. Transport costs include fixed and variable costs for car users, purchase of passes and tickets for transit users, as well as potential benefits and tax reductions. A linear regression was performed on their results to produce the specification of $T(r)$ used in this application.

${ }^{24}$ The authors have successfully calibrated and applied a monocentric model to study energy transition scenarios for the Greater Paris Region, which makes their paper an ideal source for our application.

${ }^{25}$ Viguié et al. (2014) use a slightly different boundary condition from usual: $R_{A}$ corresponds to the boundary housing rent level (i.e. the reservation housing rent below which real estate developers choose not to build) instead of the boundary land rent level. We use the same definition of $R_{A}$ in our application.

${ }^{26}$ Formally, household solvency at location $r$ is given by $\Omega(r)=(Y-R(r) s-T(r)) / Y=z / Y$. The minimum, mean and maximum values are then derived by considering the whole household population across the city. For instance, the mean solvency is equal to $\bar{\Omega}=\int_{0}^{r f} \Omega(r) n(r) d r / N$. 
We now wish to compare the effects of $\mathrm{CH}$ and $\mathrm{CH}+\mathrm{T}$ policies on utility and city size. The parameters $\alpha$ and $\mu$ are not directly comparable, however, as the scope of the budget constraint differs in each case: housing for the former, housing plus transport for the latter. We will use the mean solvency level instead to proxy the constraint level. It is an indicator that is in both cases directly related to the constraint stringency and comparable across policies. To illustrate, a mean solvency level of $70 \%$ is achieved through a value of $\alpha=0.76$ and $\mu=0.7$ (Figure 12).

For a same mean solvency level, the $\mathrm{CH}$ prudential measure always leads in the case of the Greater Paris Region to a greater utility level than the $\mathrm{CH}+\mathrm{T}$ prudential measure. Remarkably, both policies (and not only the $\mathrm{CH}$ policy) improve household utility for low to moderate constraint levels. Currently, a $\mathrm{CH}$ policy is enforced in the Greater Paris Region at a constraint level of $\alpha=0.66$, which corresponds to a mean solvency level of 59.7\% (Figure 12). For this target solvency level, equilibrium utility is equal to 471.91 in the $\mathrm{CH}$ case and 468.45 in the $\mathrm{CH}+\mathrm{T}$ case (Figure 13), against 460.6 in the unconstrained situation. This corresponds to an equivalent variation in income of $85 €(+2.8 \%)$ and $58 €(+1.9 \%)$, respectively.

Conversely, while both policies do curb urban sprawl, the effect is always greater in the case of the $\mathrm{CH}+\mathrm{T}$ policy. For a mean solvency level of $59.7 \%$ city size is $35.7 \mathrm{~km}(-11 \%)$ in the $\mathrm{CH}$ case and only $25 \mathrm{~km}(-38 \%)$ in the $\mathrm{CH}+\mathrm{T}$ case, against $40 \mathrm{~km}$ in the unconstrained case. All values are smaller than the actual size of the Greater Paris Region, which is roughly $60 \mathrm{~km}$. The underestimation of the size of the Greater Paris Region in our model may be explained by a combination of factors, starting from the fact that we consider neither protected areas nor leap-frog development. Still, it suggests that changing the current $\mathrm{CH}$ policy with a $\mathrm{CH}+\mathrm{T}$ policy at a similar level (with respect to the target solvency level) would strongly curb urban sprawl, with most likely (strongly) positive environmental impacts.

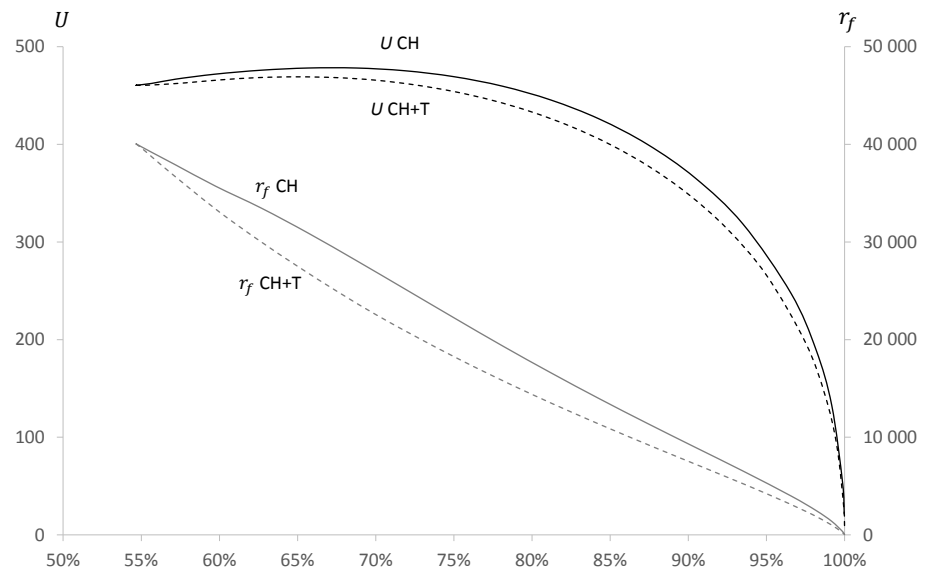

Figure 13: Effect of $\mathrm{CH}$ and $\mathrm{CH}+\mathrm{T}$ policies on equilibrium utility and city size (Greater Paris Region)

Note: Equilibrium utility and city size are represented as a function of the mean solvency level (see discussion above).

\section{Discussion}

We have shown that both prudential measures—namely capping either the housing expense ratio or the joint housing plus transport expense ratio- have two main effects: 1) they distort households' residential choices and reduce housing consumption, and 2) they lower housing prices by limiting the household bidding capacity. In as much as housing supply is price elastic, the decrease in housing prices also leads to lower construction. 
Regarding household welfare, the distortions of housing supply and demand both tend to decrease utility, while the lower housing prices tend to raise it. The relative magnitude of these effects depends on the constraint level (among other things), hence contrasted results. Provided that the price elasticity of housing supply is not too high, we find that $\mathrm{CH}$ policies improve household utility for low to moderate constraint levels. In the case of $\mathrm{CH}+\mathrm{T}$ policies, the utility gain is smaller than for $\mathrm{CH}$ policies, if not null. ${ }^{27}$ Indeed, $\mathrm{CH}$ policies, as they only consider housing, have a stronger downward effect on housing prices than $\mathrm{CH}+\mathrm{T}$ policies do. If the constraint is too stringent, $\mathrm{CH}$ and $\mathrm{CH}+\mathrm{T}$ policies are both welfare worsening. ${ }^{28}$

Of course, the increase in utility - when it occurs—-has a cost: It lowers the total housing expenditure accruing to landlords. By decreasing rental prices, $\mathrm{CH}$ and $\mathrm{CH}+\mathrm{T}$ policies proceed to a form of redistribution from landlords to households similar to the public ownership case, where land rents are redistributed to households (Fujita, 1989). ${ }^{29}$

Regarding land use effects, $\mathrm{CH}$ and $\mathrm{CH}+\mathrm{T}$ policies both lead to smaller cities than when there is no market regulation through the combined reduction of housing demand and supply. While this tends to invalidate the claim that $\mathrm{CH}$ policies foster urban sprawl, $\mathrm{CH}+\mathrm{T}$ policies do reduce city size more. This is relatively intuitive, since $\mathrm{CH}+\mathrm{T}$ policies drive households toward central locations (with low housing plus transport burdens), while $\mathrm{CH}$ policies do the opposite. Additionally, $\mathrm{CH}+\mathrm{T}$ policies lead to more homogeneous densities throughout the city, whereas $\mathrm{CH}$ policies tend to steepen the density gradient.

Finally, $\mathrm{CH}+\mathrm{T}$ policies improve household solvency more efficiently than $\mathrm{CH}$ policies. The former (intrinsically) tend to equalize housing plus transport burdens across the city and thus decrease inequalities between households. Conversely, $\mathrm{CH}$ policies firstly target by design households living close to the city center, who face high housing burdens but low housing plus transport burdens (in comparison to suburban households). As a result, $\mathrm{CH}$ policies do improve household solvency on average, but tend to maintain if not increase inequalities between the households close to and distant from the CBD.

Our results are subject to a number of caveats. First, the effects of $\mathrm{CH}$ and $\mathrm{CH}+\mathrm{T}$ policies may vary depending on the constraint level and the characteristics of demand and supply. Accordingly, one should ultimately resort to numerical simulation, like in Section 6, to appraise the effects of these policies in real case studies. Ultimately, more sophisticated models such as integrated transport land use models (ITLUMs) would be required to provide very fine estimates of the policy effects, as well as account for non-trivial phenomena (disequilibrium, suboptimal households' behaviors in residential choice because of tight housing market, etc.) . This falls outside the scope of the present paper, however.

Second, transport costs are represented in a simple manner: the function $T(r)$ is the average transport budget (net of potential benefits and tax reductions), all modes considered, that a household spends on daily travel by settling at location $r$. In this sense, car ownership and mode choice decisions are already synthesized within the $T(r)$ function to some extent. Transit-friendly areas correspond to low values of $T(r)$, and conversely for car-dependent suburban areas. The assumption of a single synthetic mode is not problematic, consequently, insofar as location is a key determinant of transport costs.

Last, we have considered homogeneous households to limit model complexity. Household income is a key determinant of housing demand, however. Housing expense ratios markedly decrease with gross income (Coulombel \& Leurent, 2013; Haas et al., 2006), meaning that low-income households are more likely to be affected by $\mathrm{CH}$ and $\mathrm{CH}+\mathrm{T}$ policies. In light of our findings, it is therefore likely that high income households will benefit more from the reduction in housing prices and of any possible welfare gains, hence equity issues. To a lesser extent, household structure is another important deter-

\footnotetext{
${ }^{27}$ More specifically, the utility gain is always null in the linear city model. It may be positive in some instances, such as when land supply quickly decreases with distance to CBD (like in our application to the Paris area).

${ }^{28}$ The only exception is the case $R_{A}=0$ (no outside competition for land), which is little realistic...

${ }^{29}$ Given the analysis of the Herbert-Stevens model, utility of the closed-city model is maximized in the case of public ownership (Fujita, 1989). No other configuration of the city, including $\mathrm{CH}$ and $\mathrm{CH}+\mathrm{T}$ cities, can outperform this one in utility grounds. Yet, $\mathrm{CH}$ policies are widely enforced and accepted, while such is not the case for the public ownership of land.
} 
minant of housing demand, as well as of transport demand. Large families, due to their larger housing and transport needs, are more likely to be impacted to $\mathrm{CH}$ and $\mathrm{CH}+\mathrm{T}$ policies, while single person or DINK (Dual income no kids) households are more likely to leverage the benefits of lower housing prices. ${ }^{30}$ An ongoing work is aiming to extend the model to several household classes (including income and household size) to further investigate this issue.

Regarding public policy implications, the results of our numerical application to the Greater Paris Region clearly call for a policy change. Replacing the current prudential measure, based on a $\mathrm{CH}$ type design, with a $\mathrm{CH}+\mathrm{T}$ type design would greatly improve household solvency (by reducing inequalities) and substantially curb urban sprawl (with a predicted $27 \%$ reduction in city size), for an otherwise negligible welfare loss (predicted of $-1 \%$ in equivalent income). Our analysis has also shown $\mathrm{CH}+\mathrm{T}$ policies (and $\mathrm{CH}$ policies to a lesser extent) to be better solvency policies than another widely enforced policy, namely housing subsidies. Indeed, they lead to lower housing prices, while housing subsidies have the unintended effect of raising housing prices, thereby strongly mitigating the solvency effect of the measure (Fack, 2005). One remaining issue is how to operationalize this $\mathrm{CH}+\mathrm{T}$ prudential rule. As a matter of fact, one advantage of $\mathrm{CH}$ policies is that they are easily enforced: all elements required to compute the prudential ratio (i.e., household gross income and rent or monthly mortgage instalment) are available by the time of the housing choice.While such is not the case for transport costs, tools have been developed to help determine one's prospective transport costs depending on the location choice. ${ }^{31}$ Using such tools or simple rules based on the future commuting distance and mean kilometric costs, one may get an estimate of transport costs to be included within the prudential calculation. The $\mathrm{CH}+\mathrm{T}$ design could then be implemented either as a hard rule (i.e., as a maximum housing plus transport ratio) or as an incentive measure (e.g., by raising home loan size in central or transit-friendly areas). ${ }^{32}$

\section{$8 \quad$ Acknowledgments}

This research was funded by the Fondation pour les Sciences Sociales, under the aegis of the Fondation de France. I would like to address my thanks to François Héran, its scientific head, and to the laureates of the $2^{\text {ime }}$ Journée pour les Sciences Sociales, who greatly contributed to improving this work. I would also like to address special acknowledgments to Marjorie Raimond, Fabien Leurent, Andrew Byrd, Harris Selod and Thomas Piketty for providing helpful support and comments for this paper.

\footnotetext{
${ }^{30}$ Divorced families are especially likely to face adverse effects, as they combine high housing needs (in particular in the case of shared custody) to lower incomes than non-divorced families.

${ }^{31}$ See for instance the $\mathrm{H}_{+} \mathrm{T}^{\circledast}$ index in the U.S. (http://htaindex.cnt.org/) or the E-MOB tool in France (http://www.e-mob.fr/ ).

32 The idea of raising home loan size in transit-friendly areas was put to practice in the U.S. under the name of "Location Efficient Mortgage". Its implementation was confined to a limited number of metropolitan areas.
} 


\section{References}

Berri, A. (2007). Residential location and household expenditures on transport and housing: The example of the Greater Paris Region. Presented at the 11th World Conference on Transport Research, Berkeley, CA. Retrieved from http://trid.trb.org/view.aspx?id=885631

Bertaud, A., \& Brueckner, J. K. (2005). Analyzing building-height restrictions: Predicted impacts and welfare costs. Regional Science and Urban Economics, 35(2), 109-125. Retrieved from https://doi. org/10.1016/j.regsciurbeco.2004.02.004

Blackman, A., \& Krupnick, A. (2001). Location-efficient mortgages: Is the rationale sound? Journal of Policy Analysis and Management, 20(4), 633-649. Retrieved from https://doi.org/10.1002/pam.1021

Brueckner, J. K. (2009). Government land use interventions: An economic analysis. In S. V. Lall, M. Freire, B. Yuen, R. Rajack, \& J.-J. Helluin (Eds.), Urban Land Markets (pp. 3-23). Netherlands: Springer. Retrieved from http://link.springer.com/chapter/10.1007/978-1-4020-8862-9_1

Cheshire, P., \& Sheppard, S. (2005). The introduction of price signals into land use planning decision-making: A proposal. Urban Studies, 42(4), 647-663. Retrieved from https://doi. org/10.1080/00420980500060210

Coulombel, N., \& Leurent, F. (2013). Les ménages arbitrent-ils entre coût du logement et coût du transport: Une réponse dans le cas francilien. Economie et Statistique, 457-458, 57-75.

Duca, J. V., \& Rosenthal, S. S. (1994). Borrowing constraints and access to owner-occupied housing. Regional Science and Urban Economics, 24(3), 301-322. Retrieved from https://doi.org/10.1016/01660462(93)02041-Z

Fack, G. (2005). Pourquoi les ménages pauvres paient-ils des loyers de plus en plus élevés ?: L'incidence des aides au logement en France (1973-2002). Economie et statistique, 381(1), 17-40. Retrieved from https://doi.org/10.3406/estat.2005.7207

Fujita, M. (1989). Urban economic theory: Land use and city size. New York: Cambridge University Press.

Gobillon, L. (2008). Une Synthèse de la Littérature sur la Consommation de Logement des Ménages.

Gobillon, L., \& le Blanc, D. (2008). Economic effects of upfront subsidies to ownership: The case of the Prêt à Taux Zéro in France. Journal of Housing Economics, 17(1), 1-33. Retrieved from https:// doi.org/10.1016/j.jhe.2007.06.003

Haas, P. M., Makarewicz, C., Benedict, A., Sanchez, T. W., \& Dawkins, C. J. (2006). Housing \& transportation cost trade-offs and burdens of working households in 28 metros. Chicago: Center for Neighborhood Technology.

Hare, P. H. (1995). Clunker Mortgages and Transportation Redlining: How the mortgage banking industry unknowingly drains cities and spreads sprawl (p. 21). Washington, DC: Patrick H. Hare Planning and Design.

Muth, R. F. (1969). Cities and housing: The spatial pattern of urban residential land Uue. Chicago: University of Chicago Press.

Polacchini, A., \& Orfeuil, J.-P. (1999). Les dépenses des ménages franciliens pour le logement et les transports. Recherche - Transports - Sécurité, 63, 31-46. Retrieved from https:/doi.org/10.1016/ S0761-8980(00)80039-4

Turner, M. A., Haughwout, A., \& van der Klaauw, W. (2014). Land-use regulation and welfare. Econometrica, 82(4), 1341-1403. Retrieved from https://doi.org/10.3982/ECTA9823

Viguié, V., Hallegatte, S., \& Rozenberg, J. (2014). Downscaling long-term socioeconomic scenarios at city scale: A case study on Paris. Technological Forecasting and Social Change, 87, 305-324. Retrieved from https://doi.org/10.1016/j.techfore.2013.12.028

Zorn, P. M. (1989). Mobility-tenure decisions and financial credit: Do mortgage qualification requirements constrain homeownership? Real Estate Economics, 17(1), 1-16. Retrieved from https://doi. org/10.1111/1540-6229.00470 


\section{Appendix}

\section{$9 \quad$ Proofs}

\section{Proof of Lemma 1}

There are two possibilities. If $z(r, u) \geq \alpha Y-T(r)$, the constraint is not binding. The solution of the bid-max problem for the $\mathrm{CH}$ case is the same as for the unconstrained case, hence: $\tilde{z}(r, u)=z(r, u), \tilde{s}$ $(r, u)=s(r, u)$ and $\tilde{\Psi}(r, u)=\Psi(r, u)$.

If $z(r, u)<\alpha Y-T(r)$, the $\mathrm{CH}$ constraint (2) is binding and we have $\tilde{z}(r, u) \geq \alpha Y-T(r), \tilde{s}(r, u)=S(\alpha Y$ - $T(r), u)$ and $\tilde{\Psi}(r, u)=(1-\alpha) Y / \tilde{s}(r, u)$.

The two alternatives can be combined as follows: $\tilde{z}(r, u)=\max [z(r, u), \alpha Y-T(r)], \tilde{s}(r, u)=\min [s(r, u)$, $S(\alpha Y-T(r), u)]$ and $\Psi(r, u)=\min [\Psi(r, u),(1-\alpha) Y l \tilde{s}(r, u)]$.

\section{Proof of Proposition 1}

In line with Fujita (1989), we consider the outer boundary function $\tilde{b}(u)$ defined by:

$$
\int_{0}^{\tilde{b}(u)} \frac{L(r)}{\tilde{s}(r, u)} d r=N
$$

The function $\tilde{b}(u)$ determines the city size needed to accommodate the population of size $N$ for a given target utility $u$. Because $\tilde{s}(r, u)$ possesses the same required features as $s(r, u)$, namely $\tilde{s}(r, u)$ decreases with $u$, tends toward $+\infty$ when $\vec{u}+\infty$ and toward 0 when $\mathrm{u} \overrightarrow{0}$, one could proceed similarly to Fujita and show that $\tilde{b}(u)$ is defined on an interval $[0, \mathrm{a}[$, with possibly $\mathrm{a}=+\infty$. Furthermore, $b(u)$ strictly increases with $u$, and ranges from 0 to $+\infty$ when $\mathrm{u}$ ranges from 0 to $a$.

Then, consider the function $\tilde{R}_{\text {Bound }}(x)=\tilde{\Psi}(x, \tilde{U}(x))$ where $\tilde{U}(x)=\mathrm{b}^{-1}(x)$ for $x \in\left[0, r_{\max }\right.$ [. $\tilde{R}_{\text {Bound }}(x)$ is the land rent at the edge $x$ of a city the utility of which is chosen so as to yield the required city size $x$. Because $\tilde{b}(u)$ increases strictly with $u$, so does $\tilde{U}(x)$, entailing that $\tilde{R}_{\text {Bound }}(x)$ is strictly decreasing in $x$ (remember that $\tilde{\Psi}(r, u)$ decreases with both $r$ and $u$ ). Since $\tilde{R}_{\text {Bound }}\left(r_{\text {max }}\right)=0$ and $\tilde{R} \tilde{B o u n d}(\mathrm{x})_{\mathrm{x}^{+} 0^{+}}+\infty$, the equation $\tilde{R}_{\text {Bound }}(x)=R_{A}$ admits one and only one solution $\tilde{r}_{f}$ Finally, by taking $\tilde{u}=\tilde{U}=\left(\tilde{r}_{f}\right)$, it is trivial to check that $\left(\tilde{u}_{,}, \tilde{r}_{f}\right)$ satisfy the condition (4).

\section{Proof of Proposition 2}

Consider $0 \leq \alpha_{1}<\alpha_{2} \leq 1$. First, we show that the constrained boundary rent curve $\widetilde{R}_{\text {Bound }}\left(x, \alpha_{1}\right)$ is above the second one: $\tilde{R}_{\text {Bound }}\left(x, \alpha_{1}\right) \geq \widetilde{R}_{\text {Bound }}\left(x, \alpha_{2}\right)$. As $\forall(r, u), \tilde{s}\left(r, u, \alpha_{1}\right) \geq \tilde{s}\left(r, u, \alpha_{2}\right)$, then

$$
\begin{aligned}
& \int_{\tilde{\tilde{b}}\left(u, \alpha_{1}\right)}^{x} \frac{L(r)}{\tilde{s}(r)} d r \leq \int_{-}^{x} \frac{L(r)}{\tilde{\tilde{s}}\left(r, \alpha_{1}\right)} d r=\int_{0}^{\tilde{\tilde{b}}\left(u, \alpha_{2}\right)} \frac{L(r)}{\tilde{s}\left(r, u, \alpha_{2}\right)} d r \\
& \int_{0} d r
\end{aligned}
$$

$=N$ entails $\tilde{b}\left(u, \alpha_{1}\right) \geq \tilde{b}\left(u, \alpha_{2}\right)$, which in turn implies that the inverse functions are in reversed order, that is to say $\tilde{U}\left(x, \alpha_{1}\right) \leq \tilde{U}\left(x, \alpha_{2}\right)$.

Using the inequality $\forall(r, u), \widetilde{\Psi}\left(r, u, \alpha_{1}\right) \geq \widetilde{\Psi}\left(r, u, \alpha_{2}\right)$, we have:

$$
\begin{aligned}
& \widetilde{\Psi}\left(x, \widetilde{U}\left(x, \alpha_{1}\right), \alpha_{1}\right) \geq \widetilde{\Psi}\left(x, \widetilde{U}\left(x, \alpha_{2}\right), \alpha_{2}\right) \\
& \quad \Rightarrow \widetilde{R}_{\text {Bound }}\left(x, \alpha_{1}\right) \leq \widetilde{R}_{\text {Bound }}\left(x, \alpha_{2}\right)
\end{aligned}
$$

which is the claimed property. Considering this, Proposition 2 is straightforward as $\tilde{R}$ Bound $\left(\tilde{r}_{f}\right.$ $\left.\left(\alpha_{1}\right), \alpha_{1}\right) \leq \widetilde{R} \operatorname{Bound}\left(\tilde{r}_{f}\left(\alpha_{2}\right), \alpha_{2}\right)=R_{A}$.

\section{Proof of Proposition 3}

Let us consider a household located at $\tilde{r}_{f}\left(\alpha_{1}\right)$. If the household spends less than $\alpha_{2} Y$ on housing in the $\alpha_{1}$ city, this implies that $\tilde{r}_{f}\left(\alpha_{1}\right) \in \bar{E}_{A}\left(\tilde{u}(\alpha 1), \alpha_{2}\right)$. We then have the following relationships:

$$
\widetilde{\Psi}\left(\tilde{r}_{f}\left(\alpha_{1}\right), \tilde{u}\left(\alpha_{1}\right), \alpha_{1}\right)=\widetilde{\Psi}\left(\tilde{r}_{f}\left(\alpha_{1}\right), \tilde{u}\left(\alpha_{1}\right), \alpha_{2}\right) \text { from } \tilde{r}_{f}\left(\alpha_{1}\right) \in \bar{E}_{A}\left(\tilde{u}\left(\alpha_{1}\right), \alpha_{2}\right)
$$


$\widetilde{\Psi}\left(\tilde{r}_{f}\left(\alpha_{1}\right), \tilde{u}\left(\alpha_{1}\right), \alpha_{1}\right)=\widetilde{\Psi}\left(\tilde{r}_{f}\left(\alpha_{2}\right), \tilde{u}\left(\alpha_{2}\right), \alpha_{2}\right)=R_{A} \quad$ (boundary conditions)

$\widetilde{\Psi}\left(\tilde{r}_{f}\left(\alpha_{1}\right), \tilde{u}\left(\alpha_{2}\right), \alpha_{2}\right) \leq \widetilde{\Psi}\left(\tilde{r}_{f}\left(\alpha_{2}\right), \tilde{u}\left(\alpha_{2}\right), \alpha_{2}\right)$ due to $\tilde{r}_{f}\left(\alpha_{1}\right) \geq \tilde{r}_{f}\left(\alpha_{2}\right)$ (Proposition 2)

Combining all these relationships yields $\widetilde{\Psi}\left(\tilde{r}_{f}\left(\alpha_{1}\right), \tilde{u}\left(\alpha_{2}\right), \alpha_{2}\right) \leq \widetilde{\Psi}\left(\tilde{r}_{f}\left(\alpha_{1}\right), \tilde{u}\left(\alpha_{1}\right), \alpha_{2}\right)$, which finally implies $\widetilde{u}\left(\alpha_{2}\right) \geq \tilde{u}(\alpha 1)$.

\section{Proof of Proposition 4}

Assume first $R_{A}>0$. Continuity of $\tilde{u}(\alpha)$ is ensured on each solution interval as all formulations are continuous functions. Continuity in $\alpha=\alpha_{c r}$ is easily verified. If $\alpha=1, \alpha \tilde{\Psi}(r, u)=0$, hence $\tilde{u}(1)=0$ given that $R_{A}>0$. One can show $\tilde{\mathrm{u}}(\alpha)_{\alpha} \overrightarrow{1} 10$, so in this sense $\tilde{u}(\alpha)$ is continuous on $[1 / 2,1]$.

Moreover, according to the results from subsection 3.3.3:

$$
\alpha \in\left[\frac{1}{2}, \alpha_{c r}\right] \Rightarrow \tilde{u}^{2}=\left(\frac{1}{4}+\left(\alpha-\frac{1}{2}\right)^{2}\right) \frac{Y^{2}}{a N+R_{A}}
$$

The function $\tilde{u}(\alpha)$ strictly increases on $\left[1 / 2, \alpha_{c r}\right]$, where $\left.\alpha_{c r} \epsilon\right] 1 / 2 ; 1[$. Because $\tilde{u}(\alpha)$ is continuous on $[1 / 2,1]$, there exists $\alpha_{\max } \geq \alpha_{c r}$ with $\tilde{u}\left(\alpha_{\text {max }}\right) \geq \tilde{\mathrm{u}}\left(\alpha_{c r}\right)>\mathrm{u}^{*}$.

Showing $\alpha_{\max }>\alpha_{c r}$ is not straightforward, because determining the sign of $\partial \tilde{x}(\alpha) / \partial \alpha$ is not trivial. However, one can show that $\partial \tilde{\mathrm{x}}(\alpha) / \partial \alpha>0$ in $\alpha=\alpha_{c}$, by deriving the system satisfied by $\tilde{x}(\alpha)$ on $\left[\alpha_{c r}, 1\right]$, which is $R_{A}^{2} /(1-\alpha)^{2} Y^{2} x^{2}+2 \mathrm{a} N \tilde{x}-\alpha^{2} Y^{2}=0$. From there, substituting $\alpha_{c r}$ by its value does the deal.

Next, consider the special case $R_{A}=0$. When the opportunity cost of the land is null, the edge of the city is always located at $r_{\text {max }}=Y l a$, which is the farthest feasible location. Considering the definition of $\alpha_{c r}, \alpha_{c r}=0$. Then $\tilde{u}^{2}=\frac{1-2 \alpha+2 \alpha^{2}}{2} \frac{Y^{2}}{a N+R_{A}}$ holds true on [1/2,1 [, and is maximal when $\alpha$ tends toward 1 , with the following limit: $\tilde{u}(\alpha) \underset{\alpha \rightarrow 1}{\longrightarrow} \frac{Y}{\sqrt{2 a N}}$.

Since no equilibrium occurs when $\alpha=1$, the exact maximum cannot be reached through a decentralized equilibrium.

\section{Additional results for the $\mathrm{CH}$ model}

Analyzing the influence of $\alpha$ on housing expenses proves complex because raising $\alpha$ may lower the equilibrium utility, thereby possibly increasing unconstrained households' housing costs. Notwithstanding, 0 indicates two cases when raising $\alpha$ decreases the aggregate housing expenditure (=land rent), as well as the total differential land rent (TDR).

For reminder, the TDR is the sum of households' housing expenses, to which has been deducted the opportunity cost of land:

\section{Proposition A}

$$
T D R(\alpha)=\int_{0}^{\tilde{r}_{f}(\alpha)} L(r)\left(\widetilde{\Psi}(r, \alpha)-R_{A}\right) d r
$$

For any couple $\alpha_{1}<\alpha_{2}$ satisfying $\tilde{u}\left(\alpha_{1}\right) \leq \tilde{u}\left(\alpha_{2}\right)$, the overall amount $H\left(\alpha_{1}\right)$ of housing expenses within the $\alpha_{1}$ city is greater than $H\left(\alpha_{2}\right)$. Similarly, $\operatorname{TDR}\left(\alpha_{1}\right) \geq \operatorname{TDR}\left(\alpha_{2}\right)$.

Otherwise, if the $\alpha_{1}$ city is entirely constrained, $H\left(\alpha_{1}\right)>H\left(\alpha_{2}\right)$.

\section{Proof}

Let us start with the first case. The inequality $\tilde{u}\left(\alpha_{1}\right) \leq \tilde{u}\left(\alpha_{2}\right)$ implies that $\tilde{\Psi}\left(r, \tilde{u}\left(\alpha_{1}\right), \alpha_{1}\right) \geq \tilde{\Psi}(r, \tilde{u}$ $\left.\left(\alpha_{2}\right), \alpha_{2}\right)$ for any $r$ since $\tilde{\Psi}(r, u, \alpha)$ decreases with both $u$ and $\alpha$. Moreover, $\tilde{r}_{f}\left(\alpha_{1}\right) \geq \tilde{r}_{f}\left(\alpha_{2}\right)$ (Proposition 2), hence: 


$$
H\left(\alpha_{1}\right)=\int_{0}^{\tilde{r}_{f}\left(\alpha_{1}\right)} L(r) \widetilde{\Psi}\left(r, \alpha_{1}\right) d r \leq \int_{0}^{\tilde{r}_{f}\left(\alpha_{2}\right)} L(r) \widetilde{\Psi}\left(r, \alpha_{2}\right) d r=H\left(\alpha_{2}\right)
$$

Considering that $\tilde{\Psi}\left(r, \alpha_{1}\right)-R_{A} \geq \widetilde{\Psi}\left(r, \alpha_{2}\right)-R_{A}$, we also have $\operatorname{TDR}\left(\alpha_{1}\right) \geq \operatorname{TDR}\left(\alpha_{2}\right)$.

In the second case, corresponding to $\left[0, \tilde{r}_{f}\left(\alpha_{1}\right)\left[\epsilon E_{A}\left(\tilde{u}\left(\alpha_{1}\right), \alpha_{1}\right)\right.\right.$, all households are constrained in the $\alpha_{1}$ city, and thus in the $\alpha_{2}$ city likewise. This entails $H\left(\alpha_{i}\right)=N .(1-\alpha i) Y$ for $i=(1,2)$, and $H\left(\alpha_{1}\right)>$ $H\left(\alpha_{2}\right)$. On the other hand, the relationship between $\operatorname{TDR}\left(\alpha_{1}\right) \geq \operatorname{TDR}\left(\alpha_{2}\right)$ is undetermined. ${ }^{33}$

\section{Derivation of the equilibrium for the $\mathrm{CH}$ linear city model}

If $\alpha \leq 1 / 2$, we are faced with the unconstrained model. Because it can be treated as the special case $\alpha=1 / 2$, we will not dwell on this matter. ${ }^{34}$

This leaves the case $\alpha \geq 1 / 2$. Let us first assume that the whole city is constrained: $\tilde{r}_{f} \leq r_{\text {bind }}$. Equilibrium conditions are given by:

$$
\begin{array}{ll}
(1-\alpha) Y\left(\alpha Y-a \tilde{r}_{f}\right) / \tilde{u}^{2}=R_{A} & \text { (boundary condition) } \\
N=\int_{0}^{\tilde{r}_{f}} \frac{L(r)}{\tilde{s}(r, \tilde{u})} d r & \text { (population constraint) }
\end{array}
$$

The population constraint can be rewritten as:

$$
N=\int_{0}^{\tilde{r}_{f}} \frac{\alpha Y-a r}{\tilde{u}^{2}} d r=\frac{1}{2 a \tilde{u}^{2}}\left[-(\alpha Y-a r)^{2}\right]_{0}^{\tilde{r}_{f}}=\frac{1}{2 a \tilde{u}^{2}}\left(\alpha^{2} Y^{2}-\left(\alpha Y-a \tilde{r}_{f}\right)^{2}\right) .
$$

Using the boundary condition and noting $\tilde{x}=\tilde{u}^{2}$, we have:

$$
N=\frac{1}{2 a \tilde{x}}\left(\alpha^{2} Y^{2}-\left(\frac{R_{A} \tilde{x}}{(1-\alpha) Y}\right)^{2}\right) \Leftrightarrow \frac{R_{A}^{2}}{(1-\alpha)^{2} Y^{2}} \tilde{x}^{2}+2 a N \tilde{x}-\alpha^{2} Y^{2}=0
$$

Because $\tilde{x}>0$, the only suitable solution to this $2^{\text {nd }}$ degree equation is:

$$
\tilde{x}=\frac{(1-\alpha)^{2} Y^{2}}{R_{A}}\left(\sqrt{\left(\frac{a N}{R_{A}}\right)^{2}+\left(\frac{\alpha}{1-\alpha}\right)^{2}}-\frac{a N}{R_{A}}\right) .
$$

Last, substituting $\tilde{x}$ in the boundary condition gives:

$$
\tilde{r}_{f}=\frac{Y}{a}\left(1-(1-\alpha)\left(1+\sqrt{\left(\frac{a N}{R_{A}}\right)^{2}+\left(\frac{\alpha}{1-\alpha}\right)^{2}}-\frac{a N}{R_{A}}\right)\right) .
$$

We now specify the domain of validity of this solution, that is to say the set of $\alpha$ for which the assumption $\tilde{r}_{f} \leq r_{\text {bind }}$ holds:

$$
\begin{gathered}
\tilde{r}_{f} \leq r_{\text {bind }} \Leftrightarrow \sqrt{\left(\frac{a N}{R_{A}}\right)^{2}+\left(\frac{\alpha}{1-\alpha}\right)^{2}}-\frac{a N}{R_{A}} \geq 1 \\
\Leftrightarrow \alpha \geq \frac{\sqrt{R_{A}+2 a N}}{\left(\sqrt{R_{A}}+\sqrt{R_{A}+2 a N}\right)} .
\end{gathered}
$$

This corresponds to our condition $\alpha \geq \alpha_{c r}$.

Now let us assume $\tilde{r}_{f}>r_{\text {bind }}$ Equilibrium conditions become:

$$
\begin{array}{ll}
\left(Y-a \tilde{r}_{f}\right)^{2} / 4 \tilde{u}^{2}=R_{A} & \text { (boundary condition) } \\
N=\int_{0}^{r_{b i n d}} \frac{L(r)}{\tilde{s}(r, \tilde{u})} d r+\int_{r_{\text {bind }}}^{\tilde{r}_{f}}-\frac{L(r) \widetilde{\Psi}_{r}}{T^{\prime}(r)} d r & \text { (population constraint) }
\end{array}
$$

As previously, we can rewrite the population condition:

$$
N=\frac{1}{2 a \tilde{x}}\left(\alpha^{2} Y^{2}-\left(\alpha Y-a r_{b i n d}\right)^{2}\right)+\frac{\widetilde{\Psi}\left(r_{\text {bind }}, \tilde{u}\right)-R_{A}}{a} .
$$

Finally, using $\tilde{\Psi}\left(r_{b i n d} \tilde{u}\right)=\left(Y-a r_{b i n d}\right)^{2} / 4 \tilde{x}$ and $a r_{b \text { ind }}=(2 \alpha-1) Y$ yields:

$$
\tilde{x}=\left(\frac{1}{4}+\left(\alpha-\frac{1}{2}\right)^{2}\right) \frac{Y^{2}}{a N+R_{A}} \text { and } \tilde{r}_{f}=\frac{Y}{a}\left(1-\sqrt{1+(2 \alpha-1)^{2}} \sqrt{\frac{R_{A}}{a N+R_{A}}}\right) .
$$

\section{Additional result for the $\mathrm{CH}+\mathrm{T}$ model}

The bid rent function $\tilde{\Psi}(r, u)$ is defined as follows:

${ }^{33} T D R\left(\alpha_{\mathrm{i}}\right)=N\left(1-\alpha_{i}\right) Y-R_{\mathrm{A}} \int_{0}^{\mathrm{r} \alpha f(\alpha \mathrm{i})} L(r) d r$. The first term decreases with $\alpha$, but the second one decreases, hence the indetermination.

${ }^{34}$ See also Fujita (1989) for a treatment of this case 


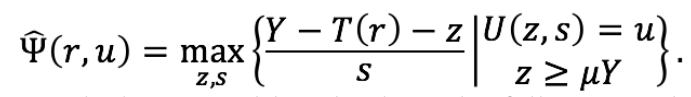

Resolution of the $\mathrm{CH}+\mathrm{T}$ bid-rent problem leads to the following solution:

$$
\left\{\begin{array}{l}
\hat{z}(r, u)=\max [z(r, u), \mu Y] \\
\hat{s}(r, u)=\min [s(r, u), S(\mu Y, u)] \\
\hat{\Psi}(r, u)=\min [\Psi(r, u),((1-\mu) Y-T(r)) / \hat{s}(r, u)]
\end{array}\right.
$$

Unlike the $\mathrm{CH}$ case, characterizing the binding zone is simple: if not empty, it is a ring located in the outer suburbs (possibly encompassing the whole city):

\section{Lemma A}

$$
\left.E_{A}(u) \text { is an interval of the form }\right] r_{\text {bind }}(u), r_{\text {max }}[\text {. }
$$

\section{Proof}

This is a direct consequence of the fact that $z(r, u)$ strictly decreases with $\mathrm{r}$. However, nothing can be said about the movement of $r_{\text {bind }}(u)$ with $u$, for the sign of $z_{u}(r, u)$ is unknown in the general case.

Setting a minimum level for the consumption of the $z$ good only affects the most remotely located households, who consume more of the housing good due to cheaper housing prices.

Furthermore, the $\mathrm{H}+\mathrm{T}$ constraint modifies the set of feasible locations. If $T(r)>(1-\mu) Y$, the $\mathrm{H}+\mathrm{T}$ constraint is automatically violated, meaning that the farthest feasible location changes from $r_{\max }$ to $\hat{r}_{\max }(\mu) r_{\text {max }}$, which is defined by $\mathrm{T}\left(r_{\max }(\mu)\right)=(1-\mu) Y$.

Bid-max variables have the same properties as in the $\mathrm{CH}$ case. On the other hand, Muth's relationship still holds if one uses new lot sizes.

\section{Proposition B}

$$
\text { If } r \in\left[0, \hat{r}_{\max }(\mu)\right] \text {, we have: }
$$

$$
\widehat{\Psi}_{r}(r, u)=-\frac{T^{\prime}(r)}{\hat{s}(r, u)}
$$

\section{Proof}

If $r \in \breve{E}_{I}(u)=\left[0, r_{\text {bind }}(u)\right.$ [ then we are faced with the unconstrained model, for which Muth's relationship obviously holds.

If $\left.\mathrm{r} \epsilon] r_{\text {bind }}(u), \hat{r}_{\text {max }}(\mu)\right]$, the constraint is active, hence $\hat{\Psi}(r, u)=((1-\mu) Y-T(r)) / \hat{s}(r, u)$. Inside the binding zone, we have $\partial \hat{s}(r, u) / \partial r=0$. Therefore, derivation of the bid-rent function gives:

$$
\widehat{\Psi}_{r}(r, u)=-\frac{T^{\prime}(r)}{\hat{s}(r, u)}=-\frac{T^{\prime}(r)}{S(\mu Y, u)} .
$$

To end the demonstration, we can easily check that Muth's relationship still holds in $r=r_{\text {bind }}(u)$ by showing that the left and right derivatives are equal in this point.

Although we obtain the standard equation for $\hat{\Psi}_{r}(r, u)$, one must bear in mind that the constrained bid-max lot size is smaller than the unconstrained one within the binding zone, with $\hat{s}(r, u)<s(r, u)$. Thus, the $\mathrm{H}+\mathrm{T}$ constraint magnifies the slope of the bid-rent function $\left(\left|\hat{\Psi}_{r}(r, u)\right|>\mid \hat{\Psi}_{r}\right.$ $(r, u) \mid)$.

The last remaining issue lies in the variations of the bid max variables relative to $u$. With a reasoning analogous to the one proposed in 3.1.2, one can show that $\hat{s}(r, u)$ increases with $u$ while $\hat{\Psi}(r, u)$ decreases with $\mathrm{u}$.

In sum, like in the $\mathrm{CH}$ case, the bid-max variables $\hat{\Psi}(r, u), \hat{z}(r, u)$, and $\hat{s}(r, u)$ retain the same variational properties as their unconstrained versions. Similarly, capping the joint housing plus transport expense ratio also decreases the bid-max lot size and the bid rent. Yet, this time it accentuates the slope 
of the bid rent function within the binding zone.

\section{Proposition C}

For any set of parameters $\left(N, Y, R_{A}\right)$ and any couple $\mu_{1}<\mu_{2}, \hat{r}_{f}\left(\mu_{1}\right) \leq \hat{r}_{f}\left(\mu_{2}\right)$.

If $R_{A}>0$ and the binding zone within either the $\mu_{1}$ or $\mu_{2}$ city is non empty (i.e., $E_{A}\left(\hat{u}\left(\mu_{i}\right)\right) \cap\left[0, \hat{r}_{f}\left(\mu_{i}\right.\right.$ )$] \neq \varnothing$ for $i=1$ or $i=2)$, then $\hat{r}_{f}\left(\mu_{1}\right)<\hat{r}_{f}\left(\mu_{2}\right)$.

\section{Proof}

The demonstration of the first point is also based on the boundary rent curve analysis. Given the similarities between the $\mathrm{CH}$ and $\mathrm{CH}+\mathrm{T}$ cases (reducing lot size and bid rent for any couple $(r, u)$ ), we can use the proof of Proposition 2 to show that $\hat{R}_{\text {Bound }}\left(\hat{r}, \mu_{1}\right) \leq \hat{R}_{\text {Bound }}\left(\hat{r}, \mu_{2}\right)$, which provides the required result. Demonstration of the second point also follows an approach identical to the one provided in Proposition 2.

\section{Derivation of the equilibrium for the $\mathrm{CH}+\mathrm{T}$ linear city model}

Assume $\hat{r}_{f} \geq r_{\text {bind }}(\mu)>0$ : the $\mathrm{H}+\mathrm{T}$ constraint is active everywhere except near the CBD. Accordingly, the equilibrium conditions become:

$$
\begin{array}{ll}
\mu Y\left((1-\mu) Y-a \hat{r}_{f}\right) / \hat{u}^{2}=R_{A} & \text { (boundary condition) } \\
N=\int_{0}^{\hat{r}_{f}} \frac{L(r)}{\hat{s}(r, \hat{u})} d r & \text { (population constraint) }
\end{array}
$$

Considering that $\hat{\Psi}_{r}^{\prime},(r, u)=-T^{\prime}(r) / \hat{s}(r, u)$, the population constraint may be rewritten as:

$$
a N=\widehat{\Psi}(0, \hat{u})-R_{A}=\frac{Y^{2}}{4 \hat{u}^{2}}-R_{A} \Rightarrow \hat{u}^{2}=\frac{1}{4} \frac{Y^{2}}{a N+R_{A}} .
$$

Hence (boundary condition):

$$
\hat{r}_{f}=(1-\mu) \frac{Y}{a}-\frac{R_{A}}{a \mu Y} \frac{1}{4} \frac{Y^{2}}{a N+R_{A}}=\frac{Y}{a}\left(1-\mu-\frac{1}{4 \mu} \frac{R_{A}}{a N+R_{A}}\right) .
$$

Now let us determine for which range of $\mu$ this solution is valid. First, $r_{b i n d}(\mu)>0$ is equivalent to $\mu<1 / 2$. Otherwise, $\hat{r}_{f} \geq r_{\text {hind }}(\mu)$ is equivalent to the following condition:

$$
\frac{Y}{a}\left(1-\mu-\frac{1}{4 \mu} \frac{R_{A}}{a N+R_{A}}\right) \geq(1-2 \mu) \frac{Y}{a} \Leftrightarrow \mu \geq \frac{1}{2} \sqrt{\frac{R_{A}}{a N+R_{A}}}=\mu_{c r} .
$$

Finally, one can easily rewrite the $\hat{r}_{f}$ formula as:

$$
\hat{r}_{f}=\frac{Y}{a}\left(1-\frac{1}{2} \sqrt{\frac{R_{A}}{a N+R_{A}}}\left(\frac{\mu}{\mu_{c r}}+\frac{\mu_{c r}}{\mu}\right)\right) .
$$

The case $0 \leq \mu \leq \mu_{c r}$, tantamount to the unconstrained model, may be treated by setting $\mu=\mu_{c r}$ in the above formulae.

This only leaves us with the case $\mu \geq 1 / 2$, where the whole city is subject to the $H+T$ constraint. The equilibrium conditions become:

$$
\begin{array}{ll}
\mu Y\left((1-\mu) Y-a \hat{r}_{f}\right) / \hat{u}^{2}=R_{A} & \text { (boundary condition) } \\
N=\int_{0}^{\hat{r}_{f}} \frac{L(r)}{\hat{s}(r, \hat{u})} d r=\hat{r}_{f} \mu Y / \hat{u}^{2} & \text { (population constraint) }
\end{array}
$$

Plugging the population constraint into the boundary condition yields:

$$
\mu Y\left((1-\mu) Y-a \hat{r}_{f}\right)=\frac{R_{A} \hat{r}_{f} \mu Y}{N} \Leftrightarrow \hat{r}_{f}=(1-\mu) \frac{Y}{a} \frac{a N}{a N+R_{A}} .
$$

Hence (population constraint):

$$
\hat{u}^{2}=\mu(1-\mu) \frac{Y^{2}}{a N+R_{A}} .
$$

